\title{
The Failure Mechanism of Recrystallization - Assisted Cracking of Solder Interconnections
}

\author{
Toni T. Mattila and Jorma K. Kivilahti \\ Aalto University \\ Finland
}

\section{Introduction}

The typical user environment load spectrum varies significantly between different electronic applications but changes in temperature are involved in nearly all of them. Owing to the increasing number of integrated high-performance functions, smartphones and handheld computers, for example, can experience significant changes in temperature during normal operation. The changes in temperature are typically caused either by internally generated heat dissipation or changes in the temperature of the environment. Today the maximum temperatures inside modern portable electronic products are in the range of $60-70{ }^{\circ} \mathrm{C}$ but occasionally they can even rise above $90{ }^{\circ} \mathrm{C}[1,2]$.

The thermomechanical reliability of electronic component boards has been one of the most studied aspects in the field for several decades. Sustained interest in this topic has endured primarily because: (a) the power densities and heat dissipation of novel electronic devices have increased; (b) electronic devices are being designed for use in ever harsher environments, such as the engine compartments of automobiles, and (c) newly developed materials whose long-term behavior in electronic applications is still unknown are continuously being introduced into electronic assemblies.

Thermomechanical strains and stresses in electronic assemblies are produced when the thermal expansion and contraction of materials is restricted. The standard thermal cycling tests extend the temperature range of electronic devices under normal operating conditions in order to accelerate the accumulation of failures. The maximum extreme temperatures in some of the standards are set to $-65{ }^{\circ} \mathrm{C}$ and $+150{ }^{\circ} \mathrm{C}$, but the conditions of $-45{ }^{\circ} \mathrm{C}$ and $+125{ }^{\circ} \mathrm{C}$ with 15- to 30-minute dwell times are most commonly used [3-5]. The coefficients of thermal expansion (CTE) of most printed wiring boards (PWB) are much higher than those of most packages. For instance, the CTE of the most commonly used PWB base material, FR-4, is about $16-17 \times 10^{-6} /{ }^{\circ} \mathrm{C}$ [6], whereas that of silicon is only $2.5 \times 10^{-6} /{ }^{\circ} \mathrm{C}$ [7]. Furthermore, because of the large volume fraction of silicon in electronic packages (see Fig. 1a), packages have much higher rigidity than PWBs and, consequently, as the component boards are exposed to changes in temperature, strains and stresses are concentrated in the solder interconnections between the packages and the PWB, as the natural expansion/contraction of the PWB is restricted by the packages (see Fig. 1b). Therefore, the reliability of most electronic products under changing thermal conditions is determined by the ability of the solder interconnections to withstand thermomechanical loads. Thermomechanical strains 
(a) BGA Package

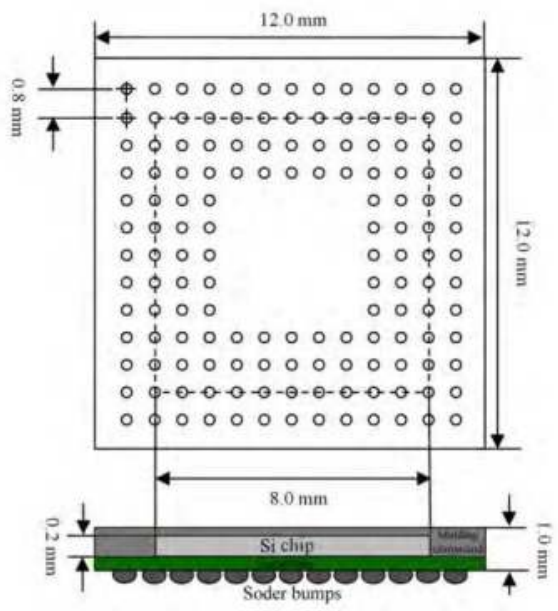

(b) Component Board Assembly

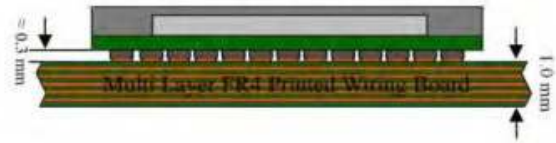

(c) Displacements under Change of Temperature

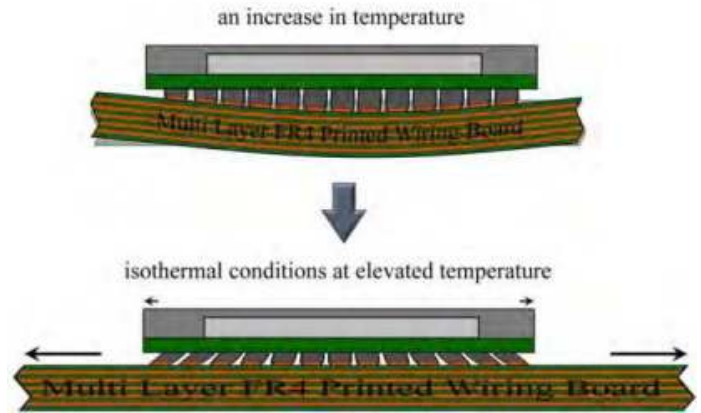

Fig. 1. a) A Ball Grid Array (BGA) package commonly used in high-density electronic devices; b) structure of the component board assembly; c) formation of strains and stresses under an increase in temperature. 
and stresses in solder interconnections are built up to different extents, of course, at all length scales, ranging from the submicron intermetallic particles submerged in the tin matrix of the tin-rich solder interconnections to the structural dimensions of a product. However, as the CTEs of most printed wiring boards is many times higher than that of most packages, the influence of strains and stresses at higher length scales (i.e. the board or the product level) are more influential.

The mechanical properties of solder interconnections are, of course, dependent on the microstructures formed during soldering but the fact that they are not stable and tend to change distinctly during the operation of products makes the evaluation of reliability a challenging task. Thus, detailed understanding of the evolution of microstructures under thermal cycling conditions and their influences on the failure of solder interconnections is essential because it can provide us with the means not only to improve reliability but also to develop more efficient and meaningful methods for the reliability evaluation of and lifetime prediction.

Despite it being a popular topic of academic research for decades, we are only beginning to understand the complexities related to the failure mechanisms of solder interconnections under cyclic thermomechanical loading. Justification for this perhaps surprising statement lies in the fact that it was only recently that the widely used tin-lead solder alloys were replaced with new lead-free materials and this change has made a comprehensive re-assessment of reliability necessary $[8,9]$. It is well known that the reliability of solder interconnections is strongly influenced by the microstructures formed during soldering and their evolution during use, but it is particularly interesting to observe that the microstructural changes in tinrich lead-free solders are markedly different from those observed in tin-lead solders, where failure takes place as a result of the heterogeneous coarsening of tin and lead phases and eventual cracking of the bulk solder (see, e.g., [10,11]). The microstructural observations of failed tin-silver-copper solder interconnections have indicated that the microstructures of solder interconnections change distinctly before cracking but by a different mechanism, namely cracking that is assisted by recrystallization (see, e.g. [12,15]).

In this chapter we discuss the failure mechanisms of tin-rich lead-free solder interconnections of electronic component boards from the perspective of the evolution of microstructures. The focus is placed on the identification of the factors driving the microstructural evolution in lead-free interconnections that creates the preconditions for the energetically feasible intergranular propagation of cracks through the interconnections. The microstrucutural approach to the reliability of electronics is useful, particularly because many failure mechanisms are related to the inevitable evolution of microstructures that takes place during the normal operation of products. Owing to the extensive research carried out over the last decade we know the microstructures and mechanical properties of many lead-free solder compositions well, but the evolution of microstructures during the operation of products has still gained little attention. However, before going into details of the changes in microstructures one should have a generalized understanding of the microstructures to be discussed when they are in an as-solidified state. Therefore we will begin this chapter with a brief overview of the solidification and microstructures of tin-rich lead-free solder interconnections formed during solidification. After that the restoration of solder interconnections and the conditions under which the recrystallization is initiated are discussed. The onset and progress of recrystallization in solder interconnections will be 
discussed in detail. The failure of the solder interconnections is discussed in a separate section to emphasize the fact that the propagation of cracks takes place after the change in microstructures as a result of recrystallization and that recrystallization significantly enhances their propagation in the solder interconnections. Finally, a method to predict the changes in microstructure and, ultimately, to predict the lifetime of solder interconnections is presented and discussed.

\section{As-solidified microstructures of tin-rich solder interconnections}

The majority of lead-free solders are based on tin (Sn), with a few alloying elements. Silver $(\mathrm{Ag})$ and copper $(\mathrm{Cu})$ are the most common major alloying elements but alloys with minor additions of elements such as nickel, antimony, indium, germanium, manganese, bismuth, zinc, or rare earth elements are also commercially available. However, for the sake of simplicity let us consider the three-component SnAgCu alloy with near-eutectic composition, which is the most commonly used solder alloy in the electronics industry.

The eutectic composition of the tin-silver-copper alloy is about Sn3.4Ag0.8Cu [13,14]. Nearly all of the solder compositions used in the electronics industry, such as the composition of $\mathrm{Sg} 3.0 \mathrm{Ag} 0.5 \mathrm{Cu}$ that is most widely used today, have silver and copper concentrations below the eutectic concentration. For such compositions, the tin-rich phase (i.e., high-tin solid solution) is formed first at the beginning of solidification and its morphology strongly affects the solidified microstructure. Owing to the high tin content of the near-eutectic $\mathrm{SnAgCu}$ alloys (more than $95 \mathrm{wt}$ \% Sn), the solidification and generated microstructures of the interconnections are most significantly influenced by the solidification of the tin-rich phase, even though in practice the tin-rich phase may or may not always be the first phase to form during solidification. This is because the dissolution of the contact metallizations changes the nominal composition of the solder and can thereby influence solidification, as will be pointed out shortly.

Figures 2a-b show an example of a cross-section of a near-eutectic $\mathrm{SnAgCu}$ solder interconnection in the as-solidified condition as imaged by employing the optical (crosspolarized) microscopy and the scanning electron microscopy. The boundaries between the contrasting areas in Figure $2 \mathrm{~b}$ are high-angle boundaries between the matrices of solidification colonies ${ }^{1}$ (the orientation difference between adjacent regions is quite large, larger than about $15^{\circ}$ ). A uniformly oriented cellular solidification structure of tin is enclosed within the colony boundaries. There is a low-angle orientation difference between the cells enclosed by the high-angle colony boundaries. The cellular structure of tin is clearly distinguishable as cells are surrounded by eutectic regions (see Fig. 2c-d). It is also noticeable that the solder interconnections, such as that shown in Figure 2, are commonly composed of a few solidification colonies of relatively uniformly oriented tin cells. [12,15] Similar observation have been made by other groups also [16,17-21].

\footnotetext{
${ }^{1}$ We have chosen to use the term "solidification colony" in order to emphasize the fact that under the reflow conditions employed, a cellular structure is generated in which the difference in crystal orientations between individual cells is small (few degrees or less). The use of this term also helps us to make a verbal distinction between the as-solidified microstructures and the recrystallized grains.
} 

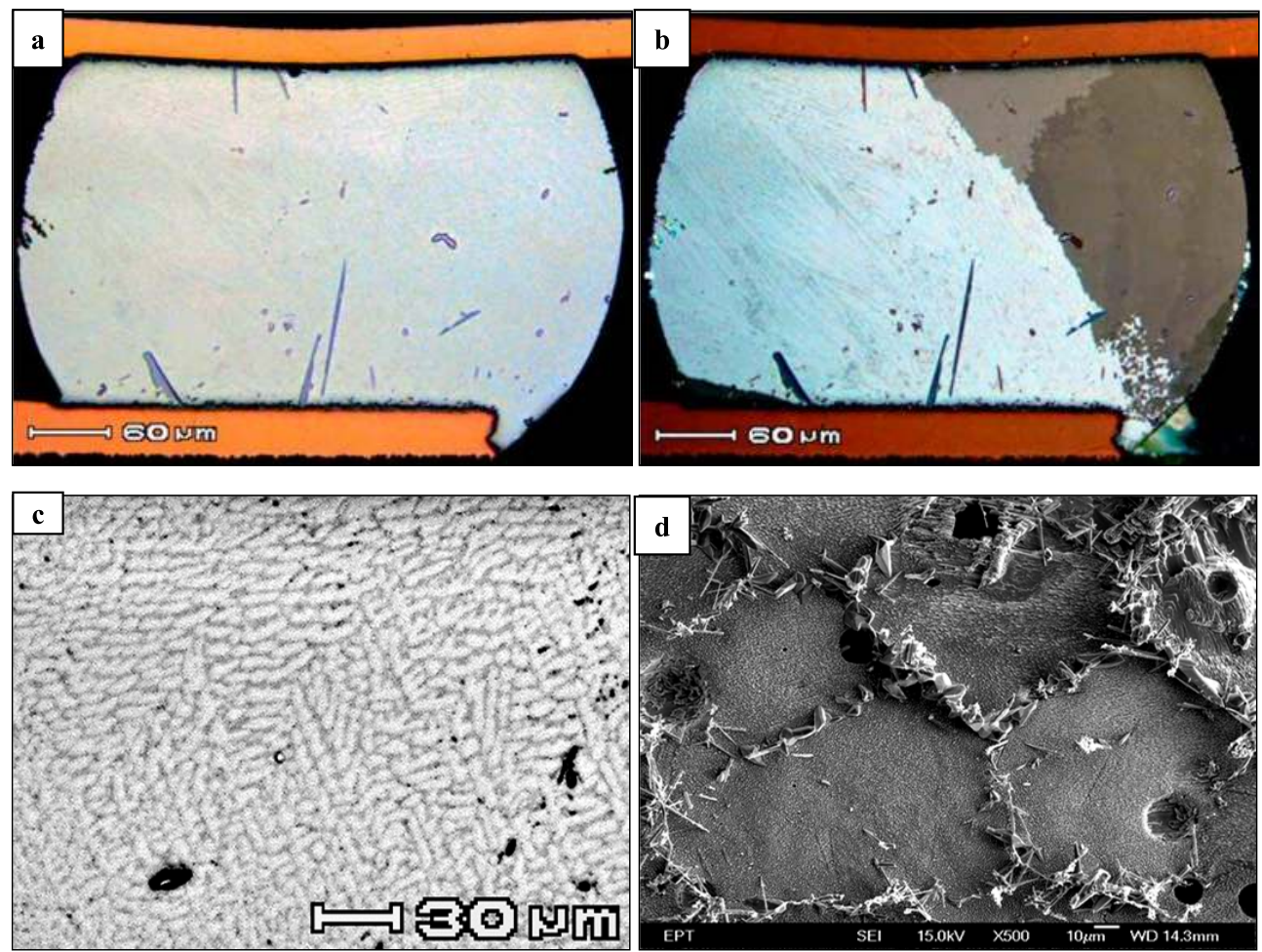

Fig. 2. The as-reflowed microstructures of a near-eutectic SnAgCu interconnection: (a) optical bright field image of a cross-section; (b) a cross-polarized light image of the same cross-section highlights the colony boundaries (high angle boundaries); (c) an SEM micrograph showing the cellular structure within a colony, where the cells are separated by low-angle boundaries; (d) the cell structure of a solidification colony is emphasized by the small intermetallic particles that surround the tin cells (the sample has been selectively etched).

Dendritic morphologies of the tin-rich phase are also reported in the literature; see e.g. [2225]. It is evident that this phase can solidify in different morphologies depending on the solidification conditions (e.g., cooling rate and metallizations in contact with the solidifying solder) and the nominal composition of the solder. The volume of the solder interconnections obviously influences the microstructures formed during solidification, as a dendritic structure of the tin-rich phase is more often observed in the case of large solder volumes, such as cast dog-bone or lap-joint pull test specimens (prepared for the mechanical characterization of solders) or packages with a relatively large $(\approx 1 \mathrm{~mm})$ bump diameter (e.g. [16,26-28]). However, the as-solidified microstructure in the near-eutectic solder interconnections in our studies has consistently been cellular, regardless of the compositions of the near-eutectic SnAgCu paste or bump alloy, contact pad metallization, package type or dimensions, or the setup parameters of our full-scale forced convection reflow soldering oven. 
In order to rationalize the formation of the observed microstructures, it is useful to examine the solidification of solder interconnections with the help of equilibrium phase diagrams. It should be kept in mind, however, that the equilibrium diagrams do not contain information about either the effect of the cooling rate or the morphology of the phases and, thus, the solidification structures are examined as equilibrium solidification ${ }^{2}$. Figure 3 presents the tin-rich corner of the $\mathrm{SnAgCu}$ phase diagram with the isothermal lines representing the liquidus temperatures, and the primary phase regions of the tin-rich phase, $\mathrm{Cu}_{6} \mathrm{Sn}_{5}$ and $\mathrm{Ag}_{3} \mathrm{Sn}$.

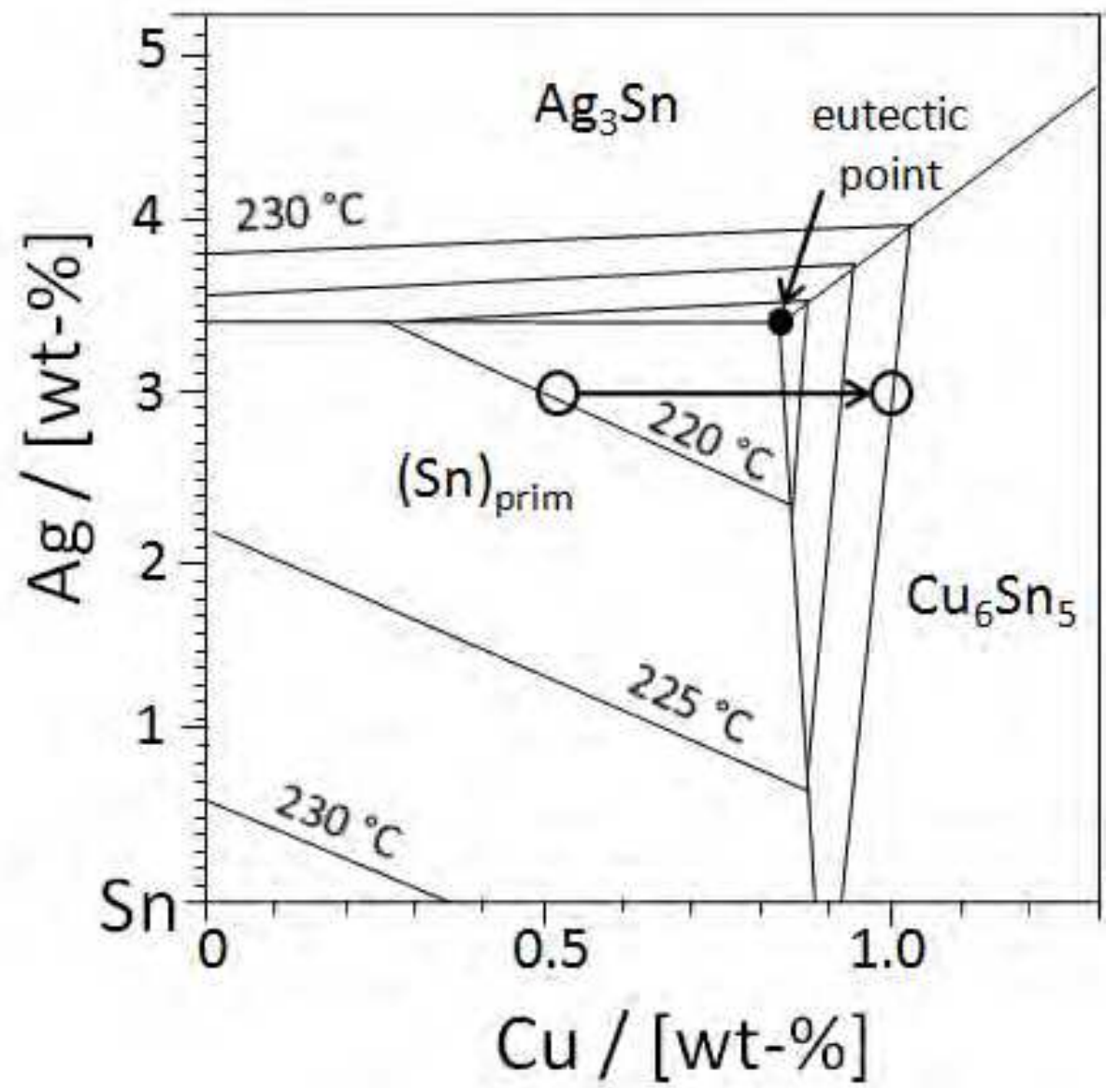

Fig. 3. Tin-rich corner of the SnAgCu phase diagram with isothermal lines and primary phase regions [29]. The arrow between the two circles represents the change in nominal composition (circle) owing to copper dissolution.

${ }^{2}$ For example, in order to take the undercooling (which will be discussed shortly) into consideration, one should extrapolate the liquidus surfaces of the $\mathrm{Cu}_{6} \mathrm{Sn}_{5}$ and $\mathrm{Ag}_{3} \mathrm{Sn}$ phase to lower temperatures and lower (or remove) the liquidus surface of the (Sn)prim. phase. 
Let us consider, for example, the composition of $\mathrm{Sn} 3.0 \mathrm{Ag} 0.5 \mathrm{Cu}$, which is a very commonly used alloy in the reflow soldering of component boards. The solidification of this composition starts with the formation of the tin-rich solution phase when the interconnections are cooled down from the peak reflow temperature to below the liquidus temperature of about $220^{\circ} \mathrm{C}$. The secondary phase, namely $\mathrm{Cu}_{6} \mathrm{Sn}_{5}$ or $\mathrm{Ag}_{3} \mathrm{Sn}$, is formed only after the nominal composition of the remaining liquid meets the curve of two-fold saturation, after which the solidification of the interconnections proceeds by the binary eutectic reaction (liquid transforms to (Sn)eut + the secondary phase; see [15] for more details).

It should also be noticed that in practice the microstructures formed on other pad metallizations can differ notably, even though the same solder compositions are used (see, e.g., $[15,30,31])$. The dissolution of the contact pads or pad metallizations of packages and printed wiring boards during reflow changes the composition of the molten solder. The influence of contact metallizations depends primarily on the dissolution rate and reactivity of the metallizations. For example, the dissolution rate of copper in near-eutectic SnAgCu solder is about $0.07 \mu \mathrm{m} / \mathrm{s}$, but that of $\mathrm{Ni}$ is more than an order of magnitude lower and can be considered negligible $[15,32,33]$. Thus, practically all nickel that is dissolved into liquid solder is used in the reaction to form intermetallic layers. However, in the cases where the solder is in direct contact with copper pads (i.e., no protective coating or organic soldering preservative is used on the copper soldering pads) the dissolution rate of copper from the pads into typical BGA solder interconnections (with a bump diameter of about $0.5 \mathrm{~mm}$ ) is high enough to lift the copper concentration above $1 \mathrm{wt}$ - $\%$ during soldering (see Fig. 3). This change in the nominal composition of the liquid can change the primary phase formed during solidification from the tin-rich phase to $\mathrm{Cu}_{6} \mathrm{Sn}_{5}$. Therefore, the as-solidified microstructures on the copper pads often show large amounts of primary $\mathrm{Cu}_{6} \mathrm{Sn}_{5}$ (hexagonal) tubes or rods in the microstructure that are absent from the microstructures of interconnections that are soldered on slow dissolution rate metallizations, such as nickel. Furthermore, interconnections soldered on copper pads, as opposed to those soldered on nickel, typically show more numerous and larger $\mathrm{Cu}_{6} \mathrm{Sn}_{5}$ particles embedded at the boundaries between the tin cells that are formed in the binary solidification, as the composition of the liquid moves a greater distance along the eutectic valley (along the curve of two-fold saturation).

There is an important consequence related to the increased copper content: the relatively large primary phase needles or particles dispersed in the solder interconnections can influence the evolution of solder interconnection microstructures. The non-coherent highangle boundaries between the $\mathrm{Cu}_{6} \mathrm{Sn}_{5}$ crystals and tin matrix provide good nucleation sites for the recrystallization. It has been previously demonstrated that the second phase particles can accelerate the nucleation of recrystallization in common structural alloys [34,35]. Readers interested in particle-stimulated nucleation of recrystallization can refer e.g. to $[36,37]$.

However, as pointed out earlier, in practice the solidification process departs somewhat from that of equilibrium solidification. Taking the undercooling into account would result in the nucleation of the $\mathrm{Cu}_{6} \mathrm{Sn}_{5}$ as a primary phase at even lower copper concentrations. Figure 4 illustrates an as-solidified microstructure of the $\mathrm{Sn} 3.0 \mathrm{Ag} 0.5 \mathrm{Cu}$ solder interconnection. It is interesting to observe that the primary $\mathrm{Cu}_{6} \mathrm{Sn}_{5}$ needles in the micrographs have the tendency to nucleate at the free surfaces of the molten interconnection, most probably on oxide 

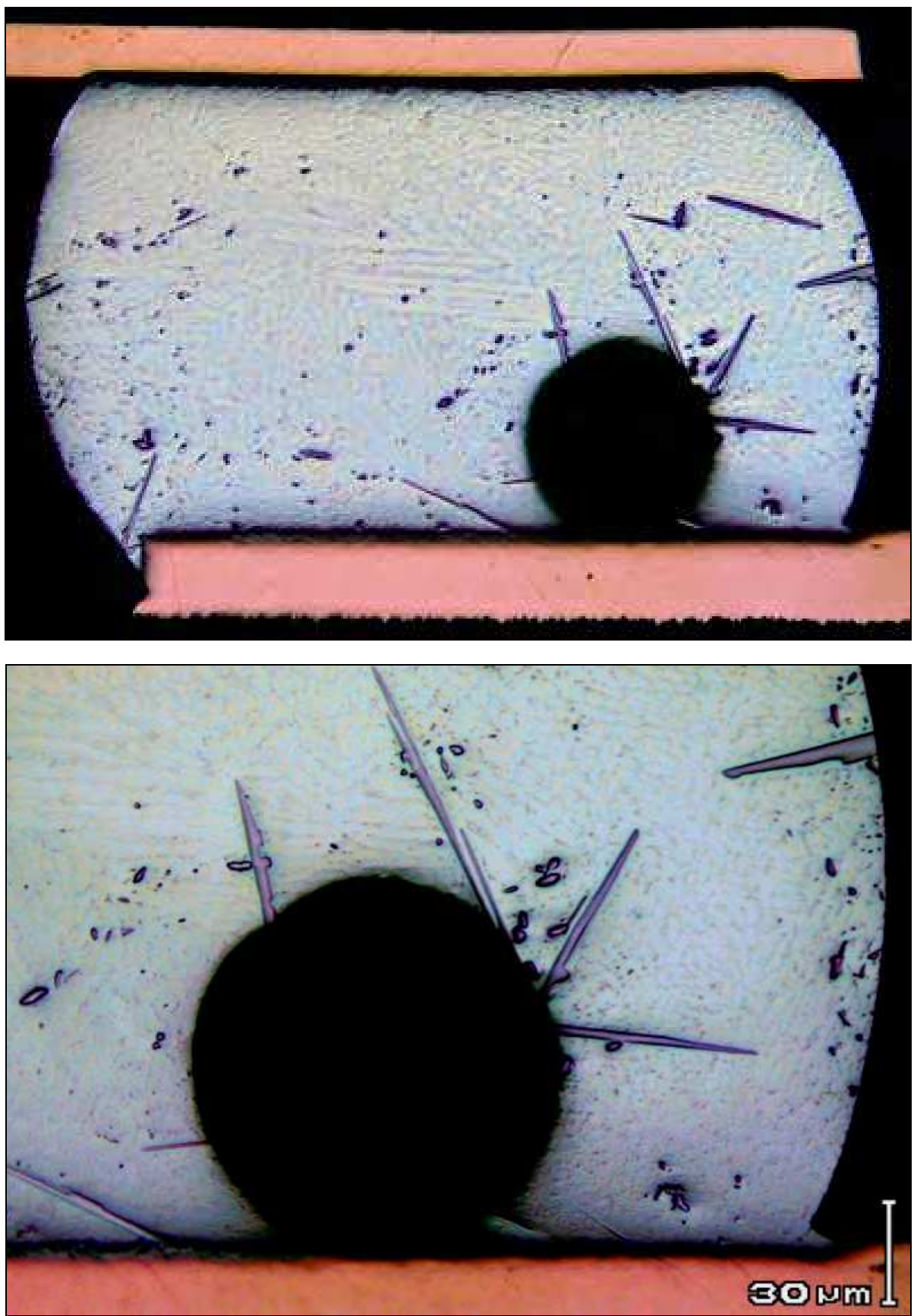

Fig. 4. As-solidified microstructure of a Sn3.0Ag0.5Cu solder interconnection illustrate how the primary $\mathrm{Cu}_{6} \mathrm{Sn}_{5}$ particles have nucleated on oxide particles on the surface of the liquid. 
particles on the liquid surfaces, instead of the package or the PWB side interfaces. It should also be mentioned, without going into detail, that it seems as if the solidification of the tinrich phase is controlled by the kinetics of heterogeneous nucleation at the surface of $\left(\mathrm{Cu}_{6} \mathrm{Sn}_{5}\right)$ intermetallic layers [38]. Darveaux et al. observed experimentally that $\mathrm{SnAgCu}$ solder alloys with a higher copper concentration exhibit a higher amount of undercooling than those with a lower concentration [39].

Before we move on to the evolution of microstructures under operating conditions, we would like to point out a few aspects to consider in more detailed investigations of the failure mechanisms of recrystallization-assisted cracking of solder interconnections. It is particularly noteworthy that the $\mathrm{Cu}_{6} \mathrm{Sn}_{5}$ or the $\mathrm{Ag}_{3} \mathrm{Sn}$ phase can nucleate with minimum undercooling in the liquid SnAgCu interconnections [40-42] but the nucleation of the tin-rich phase results in a significantly wide range of undercooling that can extend up to $60{ }^{\circ} \mathrm{C}$ [4348]. The large amounts of undercooling indicate apparent difficulties in the nucleation of tin crystals in the liquid, which can be one of the reasons why there are very often only few orientations of the Sn-rich phase observed on a cross-section of solder interconnections. The tendency to form only a few large crystals, which can be several hundred micrometers in diameter, has been observed in interconnections of various length scales, ranging from about $100 \mu \mathrm{m}$ (the diameter of a Flip Chip interconnection) to millimetre scale (lap-joint specimens used in material characterization) [15-20,28,49]. Furthermore, the fact that sometimes neighboring regions of a cross-section share a twinning relationship (indicated by a misorientation angle of about $60^{\circ}$ between adjoining regions) suggests that these crystals originate from a common nucleus and, thus, the number of different crystals can be even smaller that the amount determined by the commonly employed qualitative method of cross-polarized light microscopy $[16,20,21]$.

What has been stated above indicates clearly that mechanical behavior of solder interconnections is most probably quite different from that of a "normal" polycrystalline material. As has been pointed out and is currently being studied by many authors, the fact that the physical and mechanical properties of the tin-rich phase exhibit significant anisotropic behaviour ${ }^{3}$ can cause severely non-homogeneous deformation and the formation of internal stresses in the solder interconnections [52-54]. As the internally produced strains and stresses are combined with the higher-level strains and stresses, as caused by the differences in the coefficients of thermal expansion of printed wiring boards and packages, it is clear that the thermomechanical response of the solder interconnections becomes very complex and unique to each solder interconnection. Furthermore, the grain boundary cracking should not occur in the as-solidified structure due to the absent of high angle boundaries (other than those between colonies). This can lead to unpredictable failure sites, as reported in $[54,55]$. Therefore, when stress is applied to interconnections having this kind of microstructure, they undergo microstructural evolution before fractures can propagate. Investigations of the microstructures of failed solder interconnections have indicated that the microstructures formed during solidification are not stable and will change notably during the operation of products $[15,17,18,56-63]$.

\footnotetext{
${ }^{3}$ The coefficient of thermal expansion along the c-axis of the tetragonal unit cell $\{c / a$ ratio of about 0.5$\}$ is twice that along the other two axes $\{\mathrm{a}$ and $\mathrm{b}$-axis\}; the elastic modulus along the $\mathrm{c}$-axis is only about 0.6 times that along the other two axes [[50],[51]]
} 


\section{The role of recovery and recrystallization in the failure mechanisms of solder interconnections}

The reliability of electronic devices is commonly assessed by employing standard thermal cycling tests that place the extreme temperatures in the range of about $-45^{\circ} \mathrm{C}$ to $+125{ }^{\circ} \mathrm{C}$. The thermomechanical stresses formed in the solder interconnections under these conditions are high enough to cause instantaneous plastic deformation of the commonly used neareutectic $\mathrm{SnAgCu}$ solders [63]. Furthermore, this whole temperature range remains above the 0.3-0.4 homologous ${ }^{4}$ temperature range of the solders, which is the temperature range above which the time-dependent deformation of metals becomes significant. Thus, time spent at either elevated or lowered temperatures allows diffusion creep processes to transform the elastic strain part of the total strain into inelastic strain ${ }^{5}$. The energy stored during deformation acts as the driving force for the evolution of the microstructures.

The initiation of microstructural changes in solder interconnections is localized because of the highly non-uniform distribution of strains inside the solder interconnections. Figure 5 shows the calculated strain energy density distribution in the cornermost solder interconnection of the component board assembly shown in Figure 1. It should be pointed out that there is a difference in the rate of strain energy accumulation during thermal cycling between the solder regions on the opposite sides of the interconnections and, therefore, changes in the microstructure are observed first on the package side regions of the interconnections, where the inelastic deformation is more extensive.
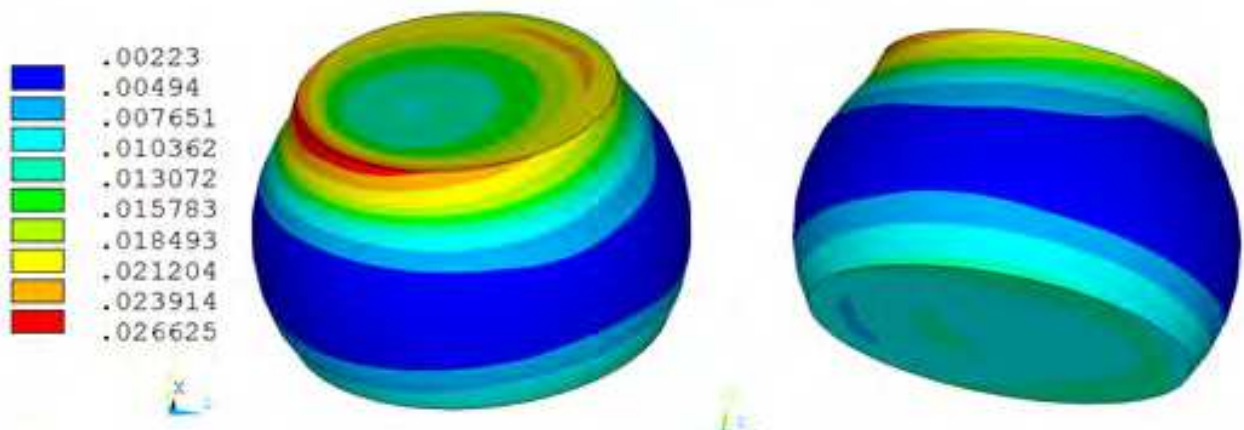

Fig. 5. Calculated strain energy density of the cornermost solder interconnections of the component board assembly sketched in Figure $1[63,64]$.

${ }^{4}$ Defined as the ratio of the prevailing temperature to the melting point of a solvent metal; both expressed in Kelvin.

${ }^{5}$ Here we consider 'total strain' $=$ elastic + inelastic strain $=$ elastic + plastic + creep strain. 
In studies reported in more detail elsewhere, the evolution of microstructures was investigated as a function of thermal cycles by taking out samples at fixed intervals during the course of the test and inspecting them for the development of microstructures and failures $[64,65]$. The results showed that the evolution of microstructures in the strain concentration regions commenced with gradual evolution of the cellular solidification structure, but after some time, i.e., the incubation period, the microstructures changed discontinuously by recrystallization. A similar observation has been reported in [66].

\subsection{Restoration of tin-rich solder alloys}

When solder interconnections are deformed plastically, a part of the work is stored in solders as lattice defects, mainly in the strain fields of dislocations. The increased internal energy of deformed solder acts as the driving force for the competing restoration processes, recovery and recrystallization. It is well known that the degree of restoration by recovery depends on the stacking fault energy of the solder alloy. At the time of writing there is little information in the literature about the recrystallization behavior of tin-based solder alloys but since the near-eutectic $\mathrm{SnAgCu}$ alloy contains more than $95 \mathrm{wt}$ \% of tin, recrystallization studies on pure tin can be considered indicative, bearing in mind that the alloying elements in solid solutions, as well as small precipitates, do affect the restoration processes. Creep studies carried out with high-purity tin have suggested that the stacking fault energy of tin is high $[67,68]$. The recovery is very effective in high-stacking fault energy metals, such as aluminum and iron, as a result of the efficient annihilation of dislocations by cross slip and climb. Therefore one can expect the restoration of high-tin solder alloys to take place to a large extent by recovery. Gay et al. and Guy have observed that pure tin (99.995\% purity) recrystallizes at room temperature even after a modest deformation (reductions of a few percent) $[69,70]$. However, in a more recent study Miettinen concluded that that even highly deformed (up to a 50\% reduction) near-eutectic $\mathrm{SnAgCu}$ solders do not recrystallize statically when annealed at $100{ }^{\circ} \mathrm{C}$ after deformation at room temperature [71]. Korhonen et al. also failed to observe recrystallization in dynamic fatigue tests performed at room temperature [72]. All these results indicate that recovery is effective also in near-eutectic $\mathrm{SnAgCu}$ solder alloys. Because recovery and recrystallization are competing processes, the progress of recovery can reduce the driving force of recrystallization significantly and recrystallization may not always initiate. On the other hand, it is well documented that neareutectic $\mathrm{SnAgCu}$ interconnections do recrystallize under dynamic loading caused by changes in temperature (between $-45^{\circ} \mathrm{C}$ and $+125^{\circ} \mathrm{C}$ ), as well as under power cycling conditions (between room temperature and $+125^{\circ} \mathrm{C}$ ) $[15,17,18,56-63,73]$. Thus, it seems that near-eutectic $\mathrm{SnAgCu}$ solder interconnections recrystallize only under restricted loading conditions: dynamic loading conditions where the strain hardening is more effective than the recovery.

Figure 6a shows a micrograph of the recrystallized microstructure on the package side neck region of a thermally cycled interconnection taken by employing optical microscopy and cross-polarized light. Figure $6 \mathrm{~b}$ shows an electron backscatter diffraction orientation map of the same surface. The black lines in the figure represent the boundaries where the crystal orientation of the adjacent grains exceeds $30^{\circ}$ and correspond well to the grain boundaries visible in the optical micrograph in Figure 6a. 

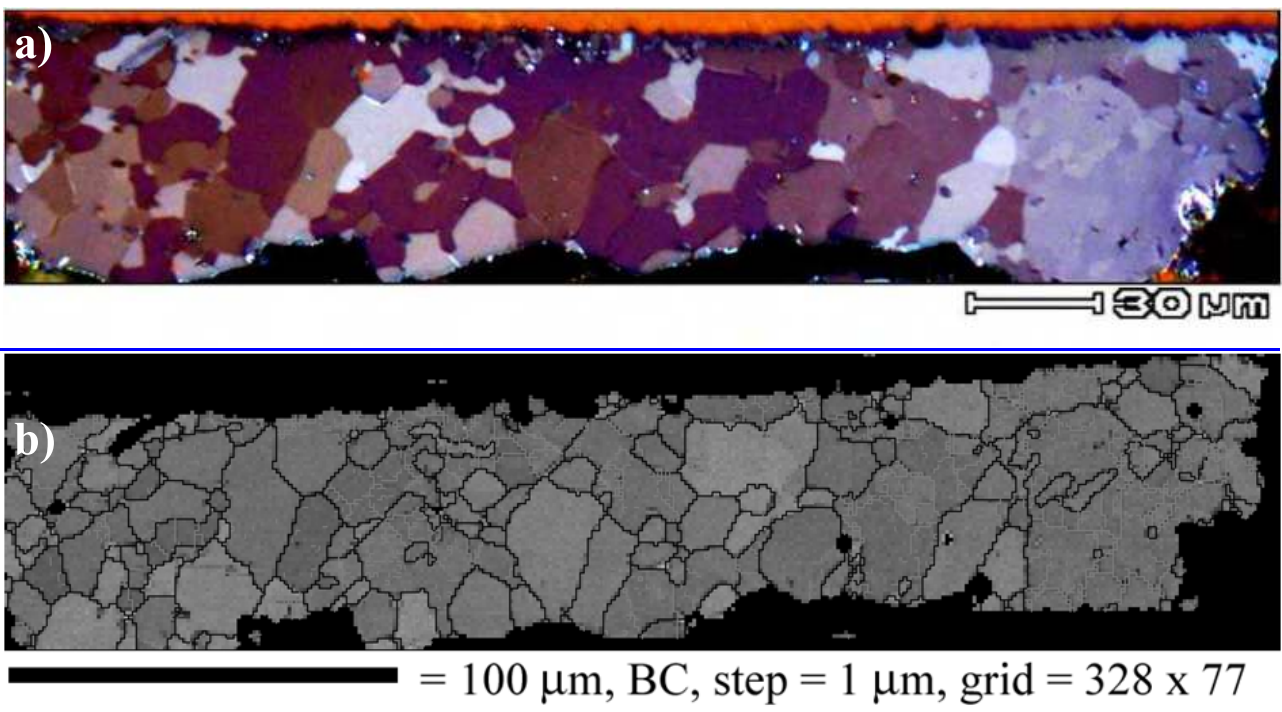

Fig. 6. a) Optical micrograph showing the recrystallized structure on the package side interfacial region of the $\mathrm{SnAgCu}$ solder interconnection taken with polarized light;

b) EBSD graph of the same location as in a) showing boundaries with large misorientation (larger than $30^{\circ} \mathrm{C}$ ) between the adjacent grains with black lines.

\subsection{Early phase of evolution: Effects of recovery and coarsening of the microstructures}

Figure 7 shows a collage of micrographs that are all taken from the same solder interconnection. It should be noticed that we are using the same interconnection to exemplify the features of microstructural evolution that take place consequently in the stress concentration regions of the solder interconnections. The evolution of microstructures on the PWB side interfacial region is much slower than the evolution on the package side of the interconnection as a result of the less extensive plastic deformation per cycle (see Fig. 5). Even though this interconnection has experienced more than 3000 cycles and failed from the package side interfacial region, the microstructures visible on the PWB side of the interconnections are very similar to those on the package side interfacial regions about 1000 to 1500 cycles earlier.

As already discussed, the as-solidified microstructures of tin-rich solder interconnections are typically composed of relatively few large tin colonies distinguished by high-angle boundaries. The cellular structure of the tin-rich colonies is clearly visible within the highangle boundaries as the individual tin cells are surrounded by eutectic regions composed of fine $\mathrm{Cu}_{6} \mathrm{Sn}_{5}$ and $\mathrm{Ag}_{3} \mathrm{Sn}$ particles. As shown in Figure $7 \mathrm{~b}$ the cellular structure of the primary tin-rich phase is still visible in the less deformed regions on the solder interconnections, such as in the middle, even after the component board has been thermally cycled until failure. However, in the strain concentration regions the tin cells begin to rearrange by the gradual coalescence of the tin cells and coarsening of the intermetallic particles (see Fig. 7c-d), during which the eutectic structures around the tin cells gradually disappear and a network 

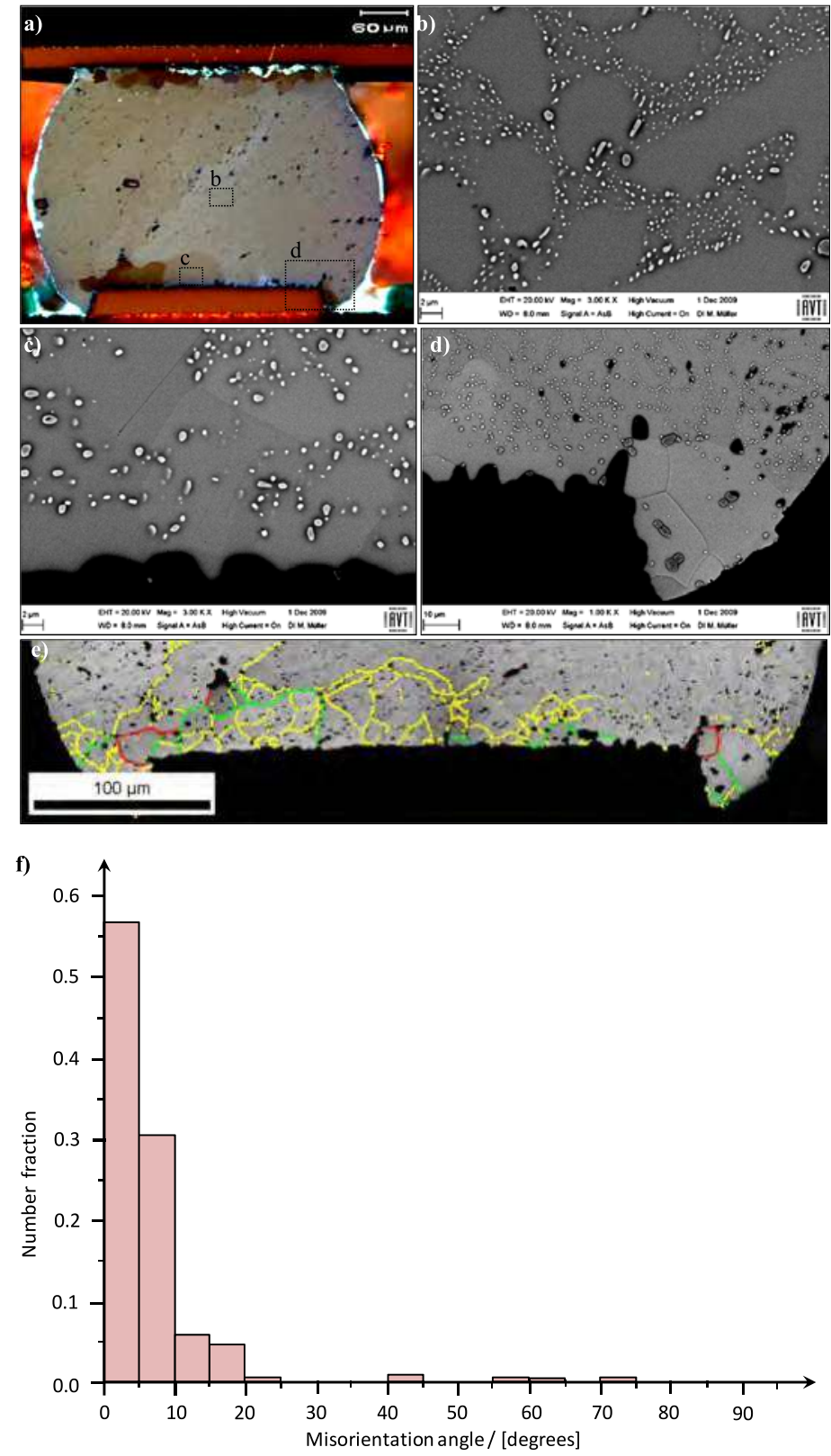

Fig. 7. a) Cross-polarized light micrograph of a solder interconnection that has failed under thermal cycling; b-d) magnifications from the regions indicated in (a); e) EBSD map of the cross-section that shows boundaries with a misorientation $<15^{\circ}$ by yellow lines, $15^{\circ}-45^{\circ}$ by green lines, and $>45^{\circ}$ by red lines; $\mathrm{f}$ ) histogram distribution of grain boundaries over the region shown in (e). $[64,65]$ 
of low-angle boundaries produced by recovery emerges. Figure 7e shows an EBSD map of the PWB side interfacial region of the same cross-section as shown in Figure 7a. The yellow lines represent the low-angle boundaries, i.e., boundaries where the crystal orientation between the adjacent grains is well below $15^{\circ}$ (see also Fig. $7 \mathrm{f}$ ). The green and red lines represent high-angle boundaries where the misorientation between adjacent grains is higher than $15^{\circ}$, the green line those between $15^{\circ}$ and $45^{\circ}$, and the red line those above $45^{\circ}$. The figure shows that in addition to the coarsening of the intermetallic particles, the formation of additional low-angle boundaries (additional to those between the cells of the Sn-rich phase formed during solidification) takes place in the regions of high strain energy density. These changes were observed to initiate early in the course of the thermal cycling tests, within about 50 to few hundred thermal cycles. It is also noteworthy that the coarsening of the intermetallic particles is strong in the regions near the high-angle grain boundaries, while the regions near the low-angle boundaries still include finer particles, comparable to the bulk of the solder ball (see Fig. 7d-e). This can be expected as the diffusion is much faster along the high-angle boundaries than it is along the low-angle boundaries.

\subsection{Later phase of evolution: Transformation of the microstructure by recrystallization}

In the course of further thermal cycling, the microstructures keep evolving gradually in the manner already described until these regions change discontinuous into more or less equiaxed grain structures by recrystallization. This change in the microstructures is first observed in the edge regions (i.e. corner regions of a cross-section) of the solder interconnections on the package side of the interconnections (the regions with the highest strain; see Fig.6) and, after the initiation of recrystallization, the recrystallized volume gradually expands from the edges toward the center, across the interconnections near the package side interfacial region of the interconnections. The incubation time of recrystallization varies significantly from one interconnection to another and even from one package to another (the same location of the interconnection) under the same loading conditions. The first indications of recrystallization in the BGA packaged board assemblies shown in Figure 1 were observed after about 500 thermal cycles but it can take up to about 2000 cycles until recrystallization is consistently observed in every interconnection in the corner regions of the packages.

Figure 8 shows a typical example of a failed interconnection, where the cracking of the solder interconnection is accompanied by a distinct change in the microstructure by recrystallization. The micrograph in Figure 8a is an optical micrograph that shows the crack path distinctly and the micrograph in Figure $8 \mathrm{~b}$ is a cross-polarized light image of the same location as Figure 8a. The comparison of the micrographs shows that the propagation path of the crack is enclosed entirely within the recrystallized region of the interconnection. Figure 8c shows an EBSD map of the same cross-section as shown in Figures 8a-b. The colour lines represent the misorientation between the adjoining regions: yellow below $15^{\circ}$, green between $15^{\circ}$ and $45^{\circ}$, and red above $45^{\circ}$. The image illustrates well the fact that the cracked region on the package side interface of the solder interconnections shows primarily high misorientations and that the high-angle grain boundaries are located very close to the crack path while, in general, the misorientations become smaller with increasing distance from the crack region. Figure 8d shows a histogram distribution of grain boundaries with different orientation over the region shown in Figure 8c (see also Fig 7f). As can be seen, the region still contains a high number of low-angle boundaries (caused by recovery) but a large 

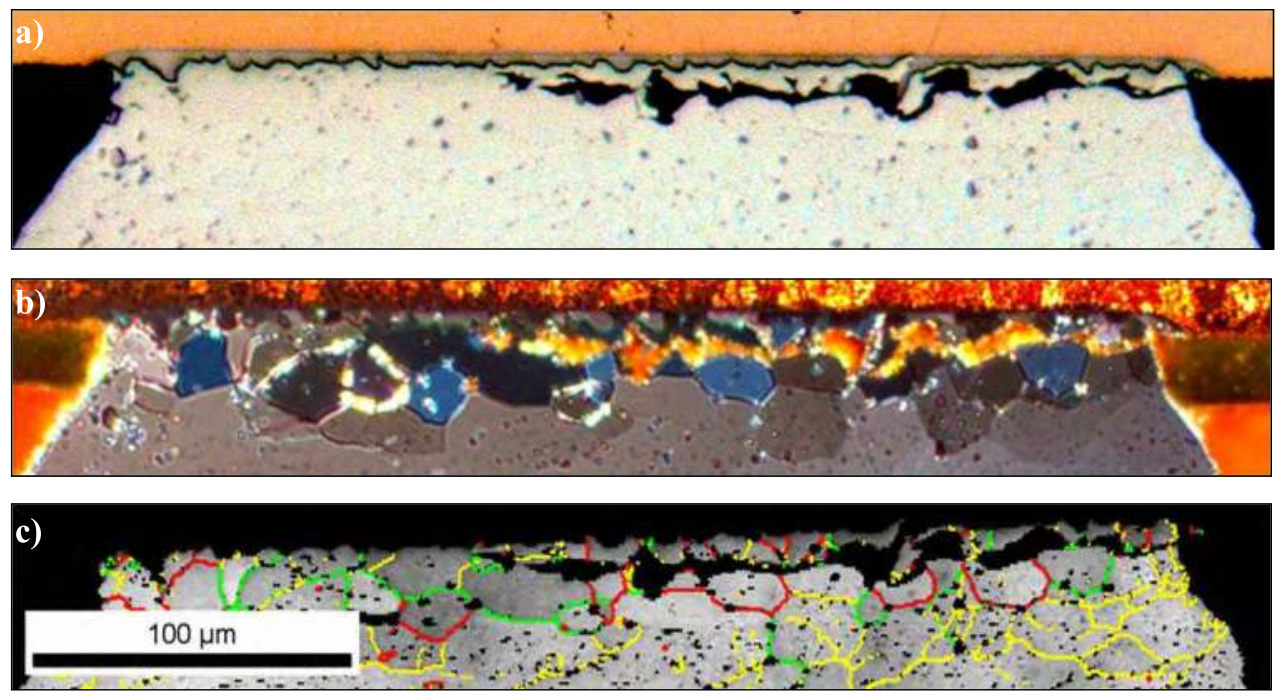

d)

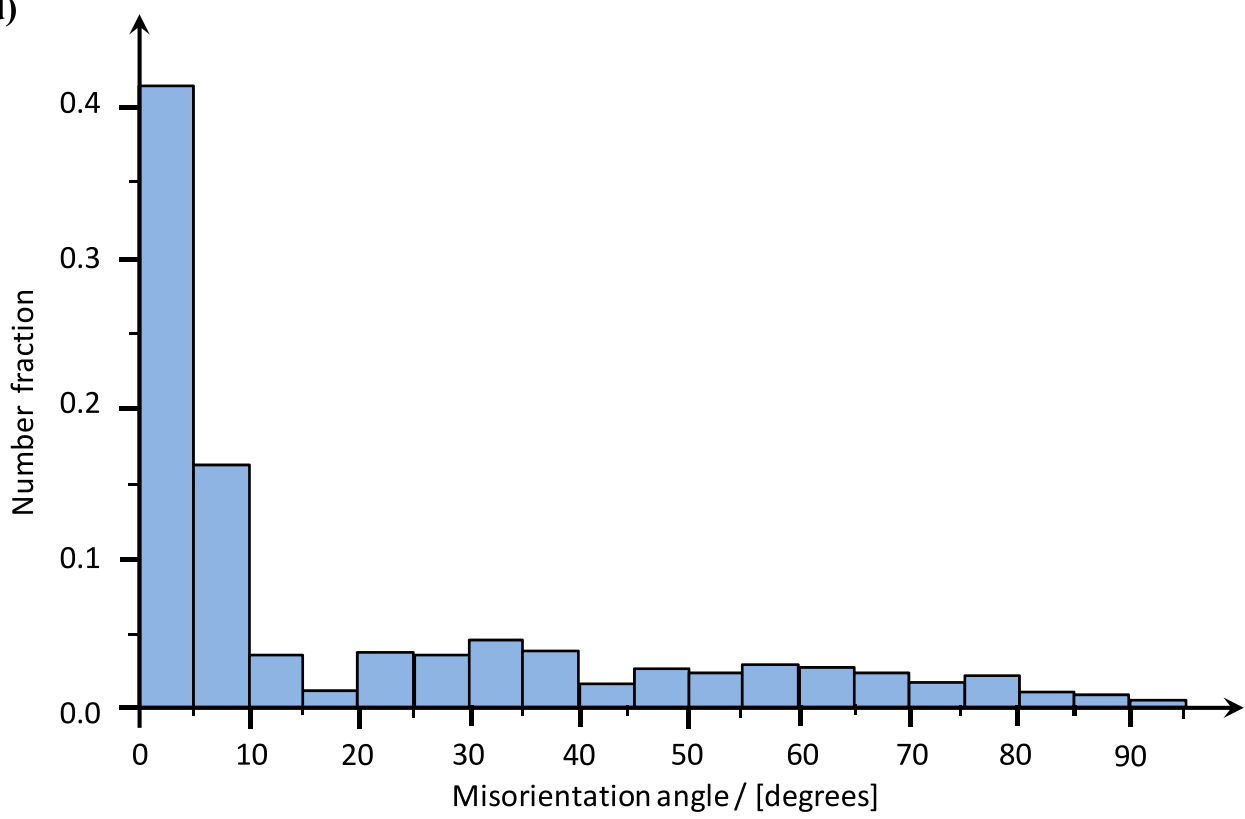

Fig. 8. a) an optical micrograph of a failed solder interconnection shows the crack path clearly (the thin black line between the gray intermetallic layer and the white solder is a contrast effect caused by specimen preparation); b) a cross-polarized light image of the same location as (a) highlights the recrystallized grains as caused by the cyclic deformation; c) EBSD map of the cross-section that shows boundaries with misorientation $<15^{\circ}$ by yellow lines, $15^{\circ}-45^{\circ}$ by green lines, and $>45^{\circ}$ by red lines; d) histogram distribution of grain boundaries over the region shown in (c). $[64,65]$ 
number of higher-angle boundaries (caused by recrystallization) have emerged. After the initiation of recrystallization in the strain concentration regions at the edges of the solder interconnections, the recrystallized volume gradually expands over the diameter of the interconnections, and cracks follow the expansion of the microstructurally changed volume. It was also observed that cracks rarely propagate outside the recrystallized volume of the solder interconnections.

\section{Cracking of recrystallized solder interconnections}

Work presented in more detail elsewhere focused on the evaluation of the nucleation time and propagation rate of cracks in BGA component board assemblies under different thermal cycling conditions $[74,75]$. Figure 9 shows the average crack lengths of the most critical solder interconnections as measured from cross-sections prepared along the diagonal line of the package as a function of thermal cycles. The different lines represent different cycling conditions (TS = thermal shock, TC = thermal cycling; the accompanying value is the dwell time of the profile in minutes).

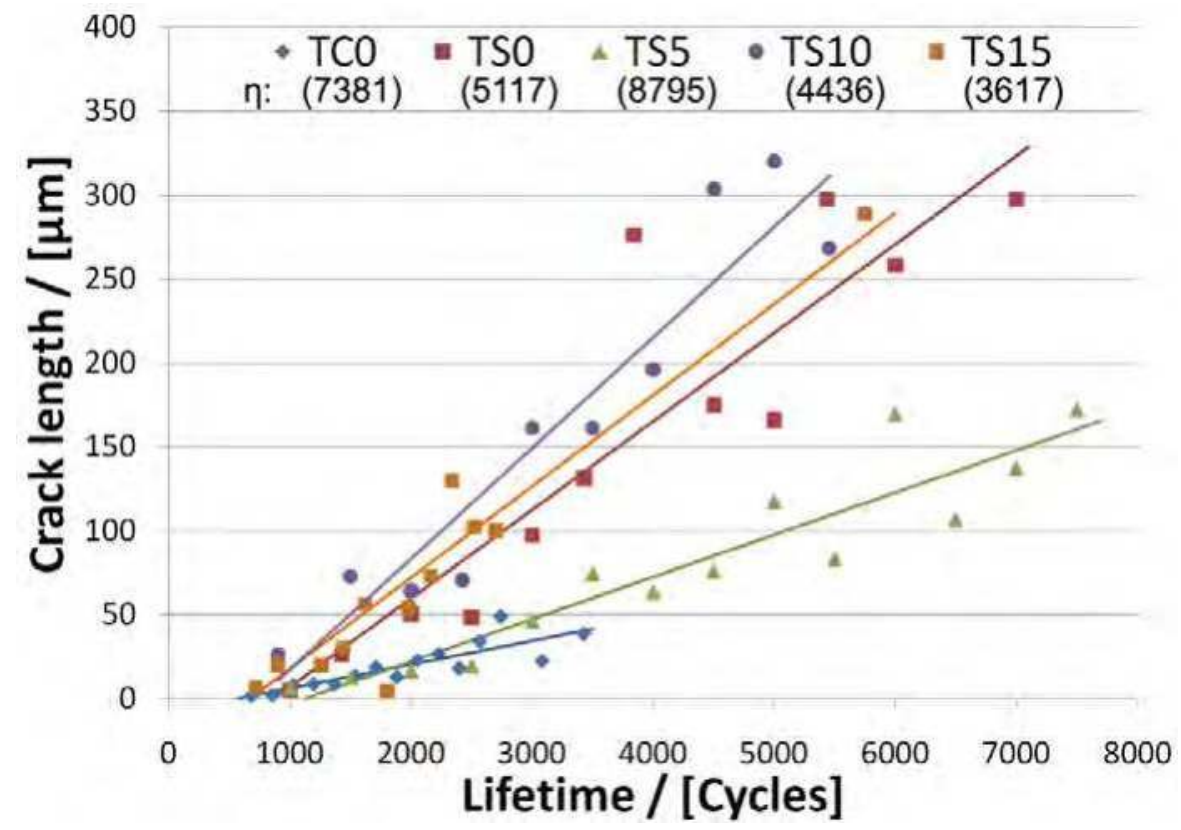

Fig. 9. Measured average crack lengths as a function of the number of thermal cycles (the numbers in parentheses are estimates of the Weibull characteristic lifetimes [n]). [74,75]

More detailed examinations showed that the nucleation of cracks in the interconnections of the BGA board assemblies took place within a relatively narrow range, between about 1000 and 1500 cycles, regardless of the dwell time or ramp rate used in the thermal cycling tests. However, the propagation rate of cracks without the influence of recrystallization was very slow. This conclusion was made based on the comparison of the measured crack lengths in interconnections that were removed from the thermal cycling oven at the same time and that 
showed or did not show recrystallization. Thus, the primary failure mechanism under thermomechanical fatigue involves the formation of a continuous network of grain boundaries by recrystallization that enables cracks to nucleate and propagate intergranularly through the solder interconnections (see Fig. 10).
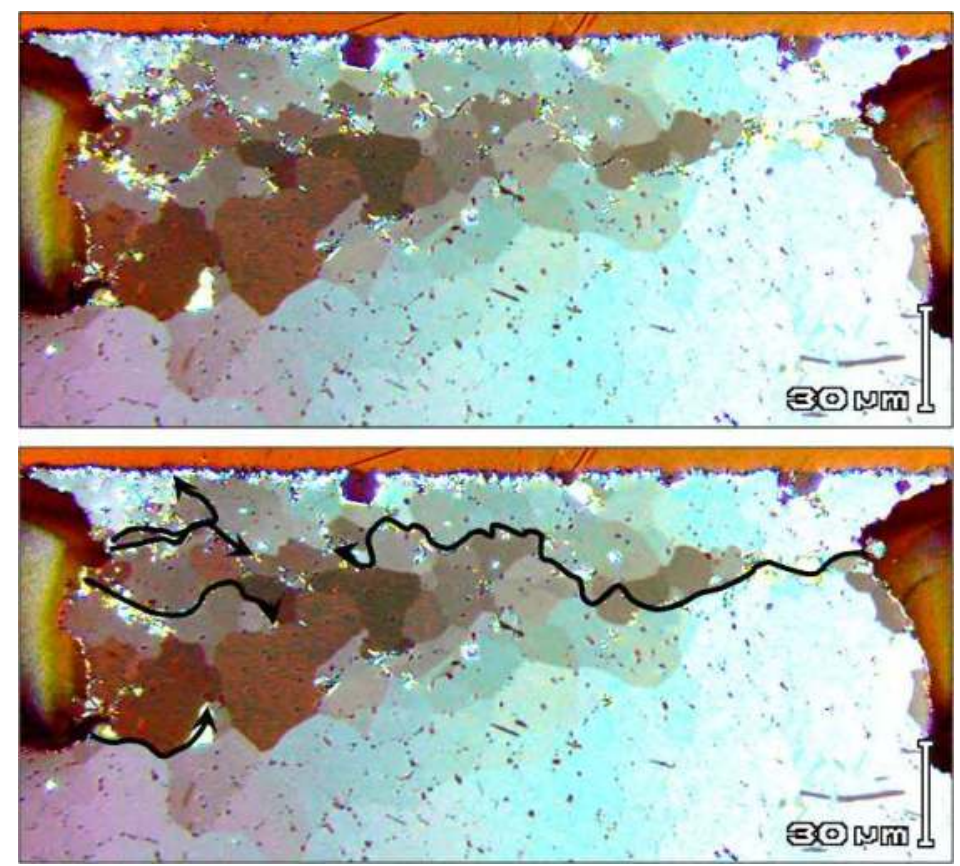

Fig. 10. Cracks propagate intergranularly between the recrystallized grains: a) cross-section of a recrystallized and cracked solder interconnection; b) the same image as in (a) but with superimposed crack paths.

The fractographic examinations illustrate the influence of recrystallization on crack propagation. Figure 11 shows the fractrographs of failed solder interconnections. The fracture surfaces exhibit a globular appearance as a result of the propagation of cracks between the recrystallized grains. Fatigue striations were occasionally observed on the inspected fracture surfaces. Although they were quite uncommon, they indicate that cracks can also propagate transgranularly under conditions when the intergranular propagation is not benignant, namely when the recrystallized grain size is larger or the stress state, orientation, and geometry of the grains are not in favor of cracking along the grain boundaries. The networks of the grain boundaries formed by recrystallization evidently provide favorable paths for cracks to propagate intergranularly with less energy consumption in comparison with transgranular propagation. It can also be expected that the cohesion between the recrystallized tin grains is lowered by grain segregation of impurities as well as locally by intermetallic particles. Furthermore, the mechanical anisotropy of the (recrystallized) tin grains can also enhance the nucleation and propagation of microcracks along their boundaries as the value of the coefficient of thermal expansion of tin singlecrystal in the $[100]=[010]$ directions is about two times that in the [001] direction [50,51]. 


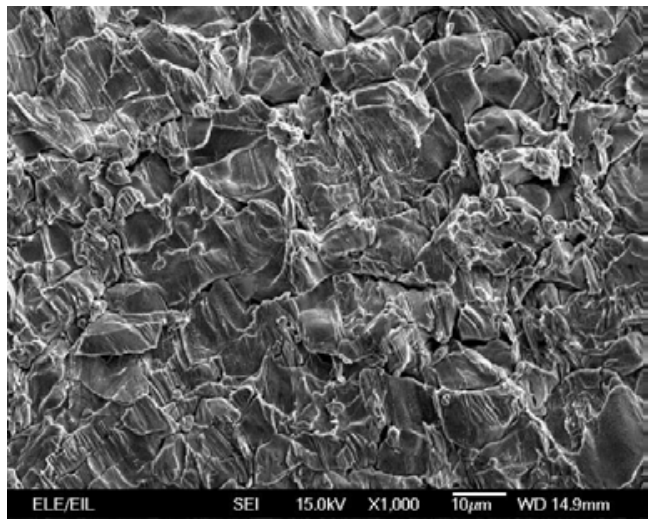

a) TS10

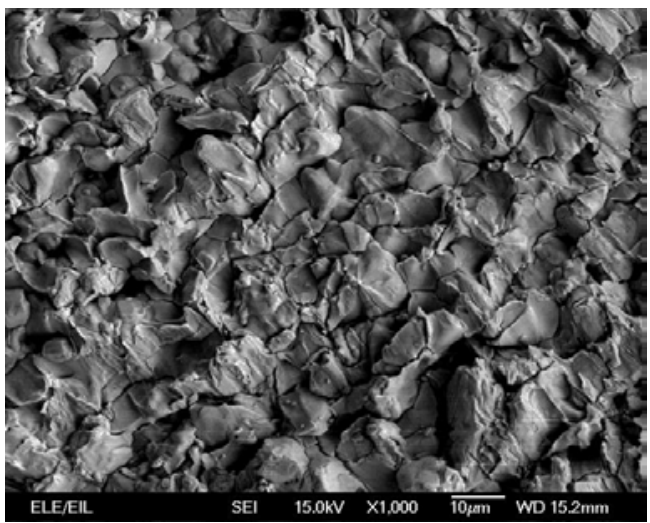

b) TS0

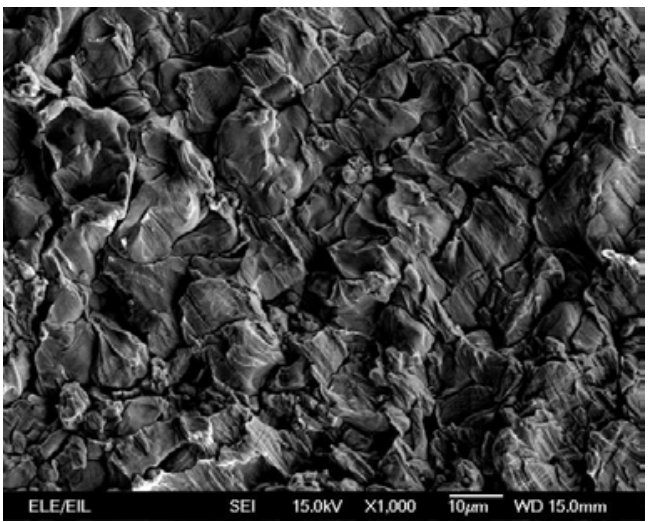

c) TC0

Fig. 11. Fractographs of the interconnections viewed from the component side [75]. Note the several secondary cracks visible in all micrographs (striations are not visible here). 
As discussed in the previous chapter, the range of the incubation periods of recrystallization in tin-rich solder interconnections is relatively large, in the range of 500 to 2000 cycles in the case of the BGA interconnections in our study. Thus, the nucleation of cracks can take place before or after the change in microstructures by recrystallization. However, the failure analyses showed that the formation of the networks of grain boundaries by recrystallization had influenced the propagation of cracks in all electrically failed interconnections. The range of 1000-1500 thermal cycles required to produce distinguishable small cracks (nuclei) equals about $25-30 \%$ of the average lifetime of the component board assemblies and, thus, cracks are in the propagation stage for about three quarters of the lifetime of component boards. Therefore, it is evident that the cracking of tin-rich solder interconnections is controlled by the rate of recrystallization.

On the basis of the results presented above we can draw two conclusions: 1) the nucleation of cracks in solder interconnections is primarily dependent on the number of load reversals. In other words, nucleation is relatively insensitive of microstructural features and their evolution, as well as the parameters of the loading conditions; 2) the rate of crack propagation is dependent on the expansion rate of the recrystallized volume. In other words, the lifetimes of solder interconnections are primarily controlled by the onset and expansion of recrystallization.

\section{An approach to lifetime prediction based on the evolution of microstructures}

A thorough understanding of the restoration process in solders can allow the development of methods for improved lifetime estimation that are based on the evolution of microstructures. Work presented in [76] describes an approach to lifetime prediction based on the competing nature of the restoration processes: under conditions in which the strain hardening is more effective than recovery, the cyclic deformation accumulates the stored energy above a critical value, after which the recrystallization can initiate. The total stored energy of the system consists of the grain boundary energy and the volume defect energy (mainly line and point defects). The stored energy is released through the nucleation and growth of new strain-free grains (grains with low defect density), which gradually consume the strain-hardened matrix of high defect density. Li et al. have developed a multiscale model based on this principle for predicting the microstructural changes of recovery, recrystallization, and grain growth in solder interconnections subjected to dynamic loading conditions $[77,78]$. The approach developed in this work is based on the principle that the stored energy of the solder is gradually increased during each thermal cycle. When a critical value of the energy is reached, recrystallization is initiated. It is assumed that, even though recovery consumes a certain amount of the energy, the net change in the energy per cycle is always positive as experimental investigations have shown that newly recrystallized grains consistently appear sooner or later under various thermal cycling conditions. The stored energy is released through the nucleation and growth of new grains, which gradually consume the strain-hardened matrix of high defect density.

The approach is realized by combining Monte Carlo simulations with finite element calculations. The Monte Carlo method is employed to model the mesoscale microstructure and the finite element method to model the macroscale non-homogeneous deformation (see 
Fig. 12). The non-homogeneous volume stored energy distribution in solder interconnections is scaled from the finite element model results and mapped onto the lattice of the Monte Carlo model. The quantitative prediction of the onset of recrystallization is carried out with the help of the Monte Carlo simulation.

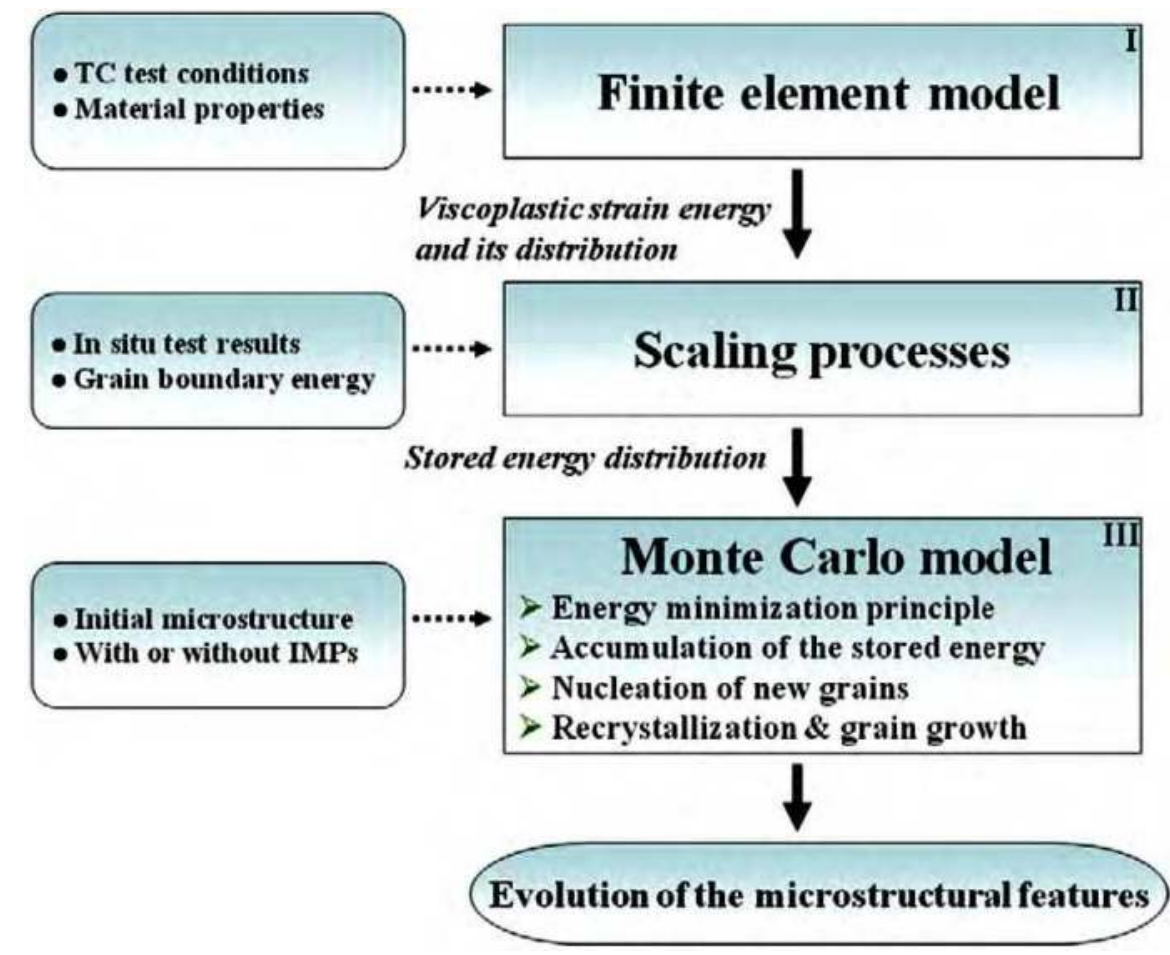

Fig. 12. Flow chart for the simulation of microstructural changes in solder interconnections $[77,78]$. Acronym TC stands for 'thermal cycling'.

In the Monte Carlo lattice, two adjacent sites with different grain orientation numbers are regarded as being separated by a grain boundary, while a group of sites with the same orientation number are considered a single grain. The total stored energy of the system under consideration consists of the grain boundary energy and the volume defect energy. Each site contributes an amount of stored energy to the system, and each pair of dissimilarly oriented neighboring sites contributes a unit of grain boundary energy to the system. The recrystallization process is modeled by randomly introducing nuclei (small embryos with zero stored energy) into the Monte Carlo lattice at a constant rate. An non-recrystallized site will become recrystallized if (a) the volume stored energy of the chosen sites is larger than the critical stored energy, and (b) the total energy of the system is reduced. If the selected site is recrystallized, it is considered as a contribution to the grain growth process.

The computational results were compared with the experimentally observed microstructural changes in solder interconnections subjected to thermal cycling tests. The results of the microstructural simulations carried out in this work can be summarized as 
follows: the incubation period of the recrystallization is about 1000 thermal cycles under the particular cycling conditions. The recrystallization is initiated in the corner regions on the package side of the solder interconnections and the expansion of the recrystallized region is controlled by the volume stored energy distribution. The expansion takes place first along the package side interfacial region toward the center of the interconnections. After that the recrystallized region expands toward the rest of the interconnections.

The incubation period of the recrystallization, the expansion of the recrystallized region, and the rate of increase of the recrystallized fraction are in good agreement with the experimental observations of thermally cycled component boards. This method predicts reasonably well the incubation period and the growth rate of the recrystallization, as well as the expansion of the recrystallized region. Figure 13 shows a comparison of predicted microstructural evolution with experimental evolution. The onset of recrystallization is a useful criterion to determine when the material models for the as-solidified microstructures are not valid anymore and, therefore, crack nucleation and propagation should be taken into account.

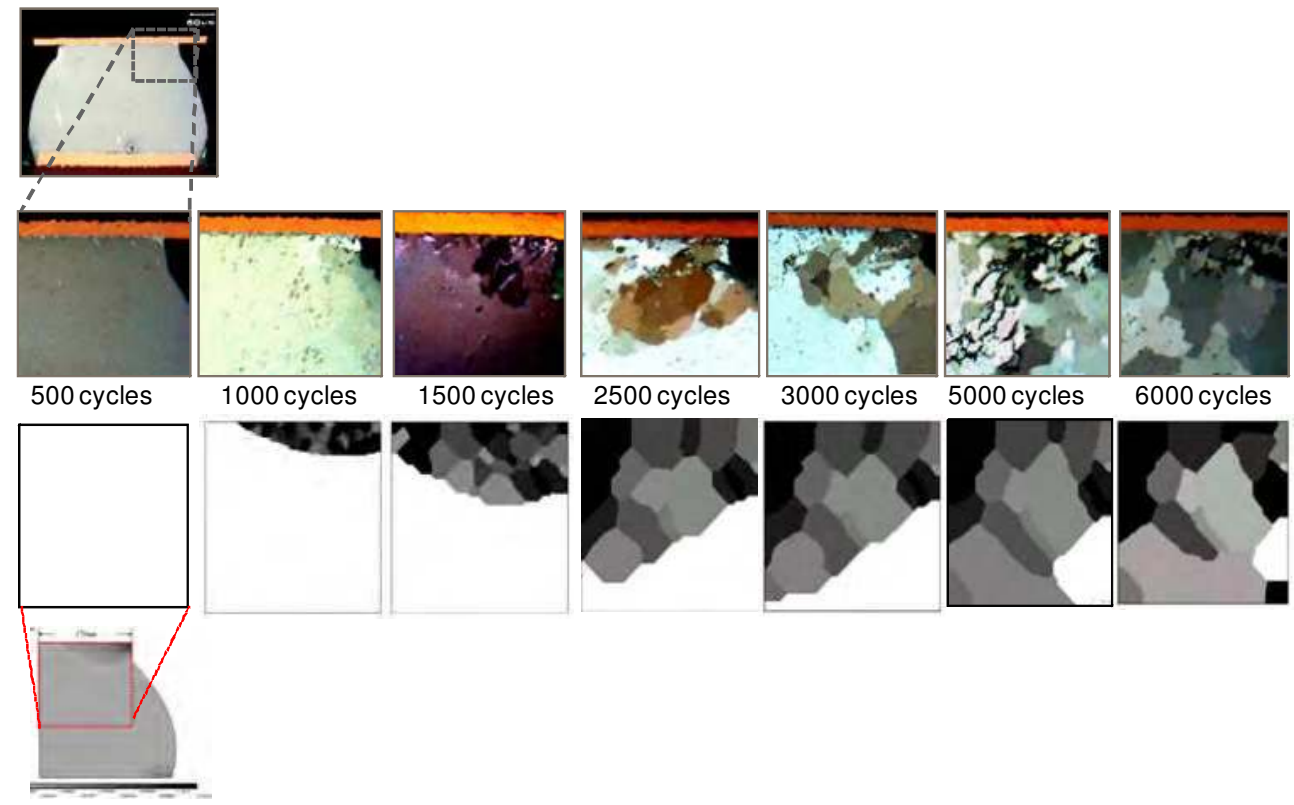

Fig. 13. Observed and simulated microstructural changes of solder interconnections with an increasing number of thermal cycles [77].

In a more recent work $\mathrm{Li}$ et al. [78] have developed the method to take into consideration the fact that the nucleation of new grains of low defect density is more likely at the boundaries of high misorientation, such as the boundary between the intermetallic particles and the tin matrix. In particular, the coarse primary intermetallic particles can generate localized stress concentrations under an applied load because of their dissimilar mechanical properties with respect to the tin matrix. The intermetallic particles are introduced in the Monte Carlo model as inert particles that also do not move or grow. In practice the fine and uniformly distributed intermetallic particles would suppress the recrystallization to some extent by 
influencing the motion of the grain boundaries of recrystallizing grains but this is not (yet) considered in the model.

\section{Conclusions}

The cracking of the near-eutectic SnAgCu interconnections under thermal cycling conditions occurs through the bulk of the solder interconnections after a change in the microstructure by recrystallization. The cumulative increase in the stored energy during each deformation cycle provides the driving force for the recrystallization. After the solidification structure has changed into a more or less equiaxed grain structure, there is a continuous network of new high-angle boundaries providing favorable sites for cracks to nucleate and propagate with less energy consumption in comparison with the cracking of the as-soldered microstructure. The decrease in the stored energy in near-eutectic $\mathrm{SnAgCu}$ solders is assumed to take place very effectively by the recovery resulting from the high stacking fault energy of tin. Therefore, the recrystallization is initiated under well-defined loading conditions: dynamic loading where strain hardening is more effective than recovery.

The recrystallization of solder interconnections under thermomechanical (or in cyclic power) loading is an important phenomenon for the following reasons: being an experimentally observable indicator of microstructural evolution, the recrystallization enables one to establish a correlation between the field use loading conditions and those produced in accelerated reliability tests. Furthermore, the theoretically well-known phenomena of recovery and recrystallization can provide the means to incorporate the effects of microstructural evolution into lifetime prediction models, which are being increasingly employed to reduce the amount of reliability testing. Finally, by controlling the recrystallization of solder interconnections, for example by alloying, one may discover new solutions to improve the reliability of soldered electronic devices.

\section{Acknowledgements}

The authors wish to thank the following people for their valuable contribution to the work presented in this chapter: Mr. Jussi Hokka, Dr. Jue Li, Dr. Maik Mueller (TU Dresden, Germany), Mr. Otso Ratia, and Dr. Hongbo Xu. The authors would also like to thank the following people for their much appreciated help and the numerous discussions over the years: Ms. Pirjo Kontio, Ms. Sini Niiranen, Ms. Johanna Koivisto, Ms. Riitta Viitala, Dr. Hongtao Chen, Dr. Erkki Heikinheimo, Mr. Simo Miettinen, Dr. Tomi Laurila, and Dr. Vesa Vuorinen. Special thanks go to Prof. Mervi Paulasto-Kröckel and Prof. Klaus-Juergen Wolter (TU Dresden, Germany) for their favorable support for this work. The financial support from the Academy of Finland (decision number 123922), the Finnish Funding Agency for Technology and Innovation (decision numbers 40135/07, 662/06, and the ELMO program), and the Finnish electronics industry is gratefully acknowledged.

\section{References}

[1] J. Karppinen, T. T. Mattila, and J. K. Kivilahti, "Formation of thermomechanical interconnection stresses in a high-end portable product," The Proceedings of the 2nd Electronics System Integration Technology Conference, London, UK, September 1-4, 2008, IEEE/EIA CPMT, (2008), pp. 1327-1332. 
[2] J. S. Karppinen, J. Li, T. T. Mattila, and M. Paulasto-Kröckel, “Thermomechanical reliability characterization of a handheld product in accelerated tests and use environment," Microelectronics Reliability, (in print).

[3] IEC 60068-2-14 Ed. 5.0 b: 1984, "Environmental testing - part 2: tests. Test N: change of temperature," International Electrotechnical Commission, (1984), $34 \mathrm{p}$.

[4] JESD22-A104C, “Temperature Cycling," Jedec Solid State Technology Association, (2005), $16 \mathrm{p}$.

[5] IPC-TM-650 rev. A, "Thermal Shock and Continuity, Printed Board," The Institute for Interconnecting and Packaging Electronic Circuits, (1997), 2 p.

[6] C. F. Coombs Jr., Printed Circuits Handbook, 5th ed., New York, (2001), McGraw-Hill, $1200 \mathrm{p}$.

[7] Y. S. Touloukian and C. Y. Ho, Thermal Expansion: Metallic Elements and Alloys, New York, (1975), IFI/Plenum, 316 p.

[8] Directive 2002/95/EC of the European Parliament and of the Council on the Restriction of the Use of Hazardous Substances in Electrical and Electronic Equipment (RoHS), Jan. 27th, 2003.

[9] Directive 2002/96/EC of the European Parliament and of the Council on Waste of Electrical and Electronic Equipment (WEEE), Jan. 27th, 2003.

[10] D. R. Frear, "Microstructural evolution during the thermomechanical fatigue of solder joints," in M.J. Cieslak, M.E. Glicksman, S. Kang, and M.E Glicksman, The Metal Science of Joining, The Minerals, Metals \& Materials Society, pp. 191-2000.

[11] J. W. Morris Jr., D. Tribula, T. S. E. Summers, and D. Grivas, “The role of microstructure in thermal fatigue of Pb-Sn solder joints," in John H. Lau, Solder Join Reliability, New York, 1991, Van Nostrand Reinold, pp. 225-265.

[12] T. T. Mattila, T. Laurila, and J. K. Kivilahti, "Metallurgical factors behind the reliability of high density lead-free interconnections," in E. Suhir, C. P. Wong, and Y. C. Lee, Micro-and Opto-Electronic Materials and Structures: Physics, Mechanics, Design, Reliability, Packaging, Springer Publishing Company, New York, 2007, (1), pp. 313350 .

[13] W. Q. Peng, "Lead-free electronic assembly based on Sn-Ag-Cu solders," Espoo, licentiate thesis, Helsinki University of Technology, (2001), p. 124.

[14] K.-W. Moon, W. J. Boettinger, U. R. Kattner, F. S. Biancaniello, and C. A. Handwerker, "Experimental and thermodynamic assessment of $\mathrm{Sn}-\mathrm{Ag}-\mathrm{Cu}$ solder alloys," Journal of Electronic Materials, 29, 10, (2000), pp. 1122-1136.

[15] T. T. Mattila, V. Vuorinen, and J. K. Kivilahti, "Impact of printed wiring board coatings on the reliability of lead-free chip-scale package interconnections," Journal of Materials Research, 19,11, (2004), pp. 3214-3223.

[16] A. LaLonde, D. Emelander, J. Jeannette, C. Larson, W. Rietz, D. Swenson, and D. W. Henderson, "Quantitative metallography of $\beta$-Sn dendrites in $5 n 3.8 \mathrm{Ag} 0.7 \mathrm{Cu}$ ball grid array solder balls via electron backscatter diffraction and polarized light microscopy," Journal of Electronic Materials, 33, 12, (2004), pp. 1545-1549.

[17] D. Henderson, J. J. Woods, T. A. Gosseling, J. Bartelo, D. E. King, T. M. Korhonen, M. A. Korhonen, L. P. Lehman, E. J. Cotts, S. K. Kang, P. Lauro, D.-Y. Shih, C. Goldsmith, and K. J. Puttliz, "The microstructure of Sn in near eutectic Sn-Ag-Cu alloy solder joints and its role in thermomechanical fatigue," Journal of Materials Research, 19, 6, (2004), pp. 1608-1612.

[18] S. Terashima and M. Tanaka, "Thermal fatigue properties of Sn-1.2Ag-0.5Cu-xNi Flip Chip interconnects," Materials Transactions, 45, 3, (2004), pp. 681-688. 
[19] S. K. Kang, P. A. Lauro, D.-Y. Shih, D. W. Henderson, and K. J. Puttlitz, "Microstructure and mechanical properties of lead-free solders and solder joints used in microelectronic applications," IBM Journal of Research and Development, 49, 4/5, (2005), pp. 607-620.

[20] A. U. Telang, T. R. Bieler, J. P. Lucas, K. N. Subramanian, L. P. Lehman, Y. Xing, and E. J. Cotts, "Grain-boundary character and grain growth in bulk tin and bulk lead-free solder alloys," Journal of Electronic Materials, 33, 12, (2004), pp. 1412-1423.

[21] L. P. Lehman, S. N. Athavale, T. Z. Fullem, A. C. Giamis, R. K. Kinyanjui, M. Lowenstein, K. Mather, R. Patel, D. Rae, J. Wang, Y. Xing, L. Zavalij, P. Borgesen, and E. J. Cotts, "Growth of Sn and intermetallic compounds in Sn-Ag-Cu solder," Journal of Electronic Materials, 33, 12, (2004), pp. 1429-1439.

[22] Z. G. Chen, Y. W. Shi, Z. D. Xia, and Y. F. Yan, "Study on the microstructure of a novel lead-free solder alloy SnAgCu-RE and its soldered joints," Journal of Electronic Materials, 31, 10, (2002), pp. 1122-1128.

[23] Maik Müller, Steffen Wiese, and Klaus-Jürgen Wolter, "Influence of cooling rate and composition on the solidification of SnAgCu solders," The Proceedings of the 1st Electronics Systemintegration Technology Conference, Dresden, Germany, September 5 - 7, 2006, IEEE/EIA CPMT, (2006), pp. 1303-1311

[24] O. Fouassier, J.-M. Heintz, J. Chazelas, P.-M. Geffroy, and J.-F. Silvain, “Microstructural evolution and mechanical properties of SnAgCu alloys," Journal of Applied Physics, 100, 043519 (2006), pp. 043519-1 - 043519-8.

[25] J. Gong, C. Liu, P. P. Conway, and V. V. Silberschmidt, “Crystallographic structure and mechanical behaviour of $\mathrm{SnAgCu}$ solder interconnects under a constant loading rate," The Proceedings of the 57th Electronic Component and Technology Conference, Reno, NV, May 29- June 1, 2007, IEEE/EIA CPMT, (2007), pp. 677-683

[26] P. Lauro, S. K. Kang, W. K. Choi, and D.-Y. Shih, "Effects of mechanical deformation and annealing on the microstructure and hardness of Pd-free solders," Journal of Electronic Materials, 32, 12, (2003), pp. 1432-1440.

[27] M. Krause, M. Mueller, M. Petzold, S. Wiese, and K. J. Wolter, "Scaling effects on grain size and texture of lead free interconnects - Investigations by electron backscatter diffraction and nanointendation," The Proceedings of the 58th Electronic Component and Technology Conference, Orlando, FL, May 27-30, 2008, IEEE/EIA CPMT, (2008), pp. 75-81.

[28] T.-M. K. Korhonen, P. Turpeinen, L. P. Lehman, B. Bowman, G. H. Thiel, R. C. Parkes, M. A. Korhonen, D. W. Henderson, and K. J. Puttlitz, "Mechanical properties of near-eutectic Sn-Ag-Cu alloy over a wide range of temperatures and strain rates," Journal of Electronic Materials, 33, 12, (2004), pp. 1581-1588.

[29] W. Peng, K. Zeng, and J. Kivilahti, "A literature review on potential lead-free solder systems," Espoo, Helsinki University of Technology, Report Series HUT-EPT-1, (2000), 53 p.

[30] S. Chada, R. A. Fournelle, W. Laub, and D. Shangguan, "Copper substrate dissolution in eutectic Sn-Ag solder and its effect on microstructure," Journal of Electronic Materials, 29, 10, (2000), pp. 1214-1221.

[31] M. O. Alam, Y. C. Chan, and K. N. Tu, "Effect of 0.5 wt\% Cu addition in Sn-3.5\% Ag solder on the dissolution rate of Cu metallization," Journal of Applied Physics, 94, 12, (2003), pp. 7904-7909.

[32] W. G. Bader, "Dissolution of $\mathrm{Au}, \mathrm{Ag}, \mathrm{Pd}, \mathrm{Pt}, \mathrm{Cu}$ and $\mathrm{Ni}$ in a Molten Sin-Lead Solder," Welding Journal, 48, 12, (1969), pp. 551s-557s. 
[33] W. G. Bader, "Dissolution and formation on intermetallics in the soldering process," The proceedings of the Conference on Physical Metallurgy and Metal Joining, St. Louis, MO, Oct. 16-17. 1980, Warrendale, USA.

[34] W. C. Leslie, T. J. Michalak, and F. W. Aul, "The annealing of cold-worked iron," in C. W. Spencer and F. E. Werner, Iron and Its Dilute Solid Solutions. New York, 1963, Interscience Puhlishers, pp. 103-119.

[35] R. W. Cahn, "Recovery and recrystallization," in R. W. Cahn, Physical Metallurgy, Amsterdam, 1965, North-Holland Publishing Company, pp. 925-987.

[36] F. J. Humphreys and M. Hatherly, Recrystallization and Related Annealing Phenomena, 2nd ed., Oxford, 2004, Elsevier Ltd., 574 p.

[37] R.D. Doherty, D. A. Hughes, F. J. Humphreys, J. J. Jonas, D. Juul Jensen, M. E. Kassner, W. E. King, T. R. McNelley, H. J. McQueen, and A. D. Rollett, "Current issues in recrystallization," Materials Science and Engineering A, 238, (1997), pp. 219 - 274.

[38] H. Yu and J. K. Kivilahti, "Nucleation kinetics and solidification temperatures of $\mathrm{SnAgCu}$ interconnections during reflow process," IEEE Transactions on Components and Packaging Technologies, 29, 4, (2006), pp. 778 - 786.

[39] R. Darveaux, C. Reichman, and P. Agrawal, "Solidification behavior of lead free and tin lead solder bumps," The Proceedings of the 60th Electronic Component and Technology Conference, Las Vegas, NV, June 1-4, 2010, IEEE/EIA CPMT, (2010), pp. 1442-1447.

[40] J. S. Kang, R. A. Gagliano, G. Ghosh, and M. E. Fine, "Isothermal solidification of Cu/Sn diffusion couples to form thin-solder joints," Journal of Electronic Materials, 31, 11, (2002), pp. 1238-1243.

[41] J.-M. Song, J.-J. Lin, C.-F. Huang, and H.-Y. Chuang, “Crystallization, morphology and distribution of $\mathrm{Ag}_{3} \mathrm{Sn}$ in $\mathrm{Sn}-\mathrm{Ag}-\mathrm{Cu}$ alloys and their influence on the vibration fracture properties," Materials Science and Engineering A, 466, (2007), pp. 9-17

[42] D. W. Henderson, T. Gosselin, A. Sarkhel, S. K. Kang, W.-K. Choi, D.-Y. Shih, C. Goldsmith, and K. J. Puttlitz, " $\mathrm{Ag}_{3} \mathrm{Sn}$ plate formation in the solidification of near ternary eutectic Sn-Ag-Cu alloys," Journal of Materials Research, 17, (2002), pp. 27752778.

[43] J. H. Perepezko, D. H. Rasmussen, I. E. Anderson, and C. R. Loper, Jr., “Undercooling of low-melting point metals and alloys," The Proceedings of the International Conference on Solidification and Casting of Metals, Sheffield, England, July 1977, Sheffield Metallurgical and Engineering Association / University of Sheffield / the Metals Society, (1979), pp. 169-174.

[44] S. Wiese, E. Meusel, and K. J. Wolter, "Microstructural dependence of constitutive properties of eutectic SnAg and SnAgCu solders," The Proceedings of the 53 Electronic Components and Technology Conference, 27 May-30 May, 2003, New Orleans, LA, IEEE EIA/CPMT, (2003), pp. 197-206.

[45] S. K. Kang, W. K. Clioi, D.-Y. Shih, D. W. Henderson, T. Gossefin, A. Sarkliel, C. Goldsmith, and K. J. Puttlitz, "Formation of $\mathrm{Ag}_{3} \mathrm{Sn}$ plates in $\mathrm{Sn}-\mathrm{Ag}-\mathrm{Cu}$ alloys and optimization of their alloy composition," The Proceedings of the 53 ${ }^{\text {rd }}$ Electronic Components and Technology Conference, 27 May-30 May, 2003, New Orleans, LA, IEEE EIA/CPMT, (2003), pp. 64-70.

[46] D. Swenson, "The effects of suppressed beta tin nucleation on the microstructural evolution of lead-free solder joints," Journal of Material Science: Materials in Electronics, 18, 1-3, (2007), pp. 39-54.

[47] S. K. Kang, G. C. Moon; P. Lauro, and D.-Y. Shih, "Critical Factors Affecting the Undercooling of Pb-free, Flip-Chip Solder Bumps and In-situ Observation of 
Solidification Process," The Proceedings of the 57th Electronic Component and Technology Conference, Reno, NV, May 29-June 1, 2007, IEEE/EIA CPMT, (2007), pp. 1597-1603.

[48] J. W. Elmer, E. D. Specht, and M. Kumar, "Microstructure and in situ observations of undercooling for nucleation of $\beta$-Sn relevant to lead-free solder alloys," Journal of Electronic Materials, 39, 3, (2010), pp. 273-282.

[49] M. A. Matin, W. P. Vellinga, and M. G. D. Geers, "Thermomechanical fatigue damage evolution in SAC solder joints," Materials Science and Engineering A, 445-446, (2007), pp. 73-85.

[50] N. S. Brar and W. R. Tyson, "Elastic and plastic anisotropy of white tin," Canadian Journal of Physics, 50, 19, (1972), pp. 2257-2264.

[51] Metals Handbook, Volume 1 - Properties and Selection of Metals, 8th ed., New York, 1961, American Society for Metals, 1300 p.

[52] K. N. Subramanian, "Role of anisotropic behavior of Sn on thermomechanical fatique and fracture of Sn-based solder joints under thermal excursions," Fatigue and Fracture of Engineering Materials and Structures, 30, 5, (2007), pp. 420-431.

[53] M. A. Matin, E. W. C. Coenen, W. P. Vellinga, and M. G. D. Geers, "Correlation between thermal fatigue and thermal anisotropy in a Pb-free solder alloy," Scripta Materialia, 53, (2005), pp. 927-932.

[54] T. R. Bieler, H. Jiang, L. P. Lehman, T. Kirkpatrick, E. J. Cotts, and B. Nandagopal, "Influence of Sn grain size and orientation on the thermomechanical response and reliability of Pb-free solder joints," IEEE Transactions on Components and Packaging Technologies, 31, 2, (2008), pp. 370-380.

[55] T. R. Bieler, B. Zhou, L. Blair, A. Zamiri, P. Darbandi, F. Pourboghrat, T.-K. Lee, and K.C. Liu, "The role of elastic and plastic anisotropy of Sn on microstructure and damage evolution in lead-free solder joints," The Proceedings of the 2011 IEEE International Reliability Physics Symposium, 10-14 April, 2011, Monterey, CA, IEEE, (2011), pp. 5F.1.1-5F.1.9.

[56] S. Terashima, K. Takahama, M. Nozaki, and M. Tanaka, "Recrystallization of Sn grains due to thermal strain in Sn-1.2Ag-0.5Cu-0.05N solder," Materials Transactions, Japan Institute of Metals, 45, 4, (2004), pp. 1383-1390.

[57] S. Dunford, S. Canumalla, and P. Viswanadham, "Intermetallic morphology and damage evolution under thermomechanical fatigue of lead $(\mathrm{Pb})$-free solder interconnections," The Proceedings of the 54th Electronic Components and Technology Conference, June 1-4, 2004, Las Vegas, NV, USA, IEEE/EIA/CPMT, (2004), pp. 726-736.

[58] L. Lehman, S. Athavale, T. Fullem, A. Giamis, R. Kinyanjui, M. Lowenstein, K. Mather, R. Patel, D. Rae, J. Wang, Y. Xing, L. Zavalij, P. Borgesen, and E. Cotts, "Growth of Sn and intermetallic compounds in Sn-Ag-Cu solder," Journal of Electronic Materials, 3, 12, (2004), pp. 1429-1439.

[59] P. Limaye, B. Vandevelde, D. Vandepitte, and B. Verlinden, "Crack growth rate measurement and analysis for WLCSP Sn-Ag-Cu solder joints," The proceedings of the SMTA international annual conference, Chicago, IL, September 25-29, (2005), pp. 371-377.

[60] L. Xu and J. H.L. Pang, "Intermetallic growth studies on SAC/ENIG and SAC/CU-OSP lead-free solder joints," Thermal and Thermomechanical Phenomena in Electronics Systems, (2006), pp.1131-1136. 
[61] A. U. Telang, T. R. Bieler, A. Zamirini, and F. Pourboghrat, "Incremental recrystallization/crain growth driven by elastic strain energy release in a thermomechanically fatigued lead-free solder joint," Acta Materialia, 55, (2007), pp. 2265-2277.

[62] J. J. Sundelin, S. T. Nurmi, and T. K. Lepistö, "Recrystallization behavior of SnAgCu solder joints," Materials Science and Engineering A, 474, (2008), pp. 201-207.

[63] J. Li, J. Karppinen, T. Laurila, and J. K. Kivilahti, "Reliability of Lead-Free solder interconnections in Thermal and Power cycling tests," IEEE Transactions on Components and Packaging Technologies, 32, (2009), pp. 302-308.

[64] H. T. Chen, M. Mueller, T. T. Mattila, J. Li, X.W. Liu, K.-J. Wolter, and M. PaulastoKröckel, "Localized Recrystallization and Cracking of Lead-Free Solder Interconnections under Thermal Cycling," Journal of Materials Research, 25, 16, (2011), pp. 2103-2116.

[65] T. T. Mattila, M. Mueller, M. Paulasto-Kröckel, and K. J. Wolter "Failure mechanism of solder interconnections under thermal cycling conditions," The Proceedings of the 3rd Electronic System-Integration and Technology Conference, Berlin, Germany, September 13-16, 2010, IEEE/EIA CPMT, (2010), pp. 1-8.

[66] B. Zhou, T. T. Bieler, T. K. Lee, and K.C. Liu, “Crack development in a low-stress PBGA package due to continuous recrystallization leading to formation of orientations with [001] parallel to the interface," Journal of Electronic Materials, 39, (2010), pp. $2669-2679$.

[67] D. Hardwick, C. M. Sellars, and W. J. McG. Tegart, "The occurrence of recrystallization during high-temperature creep," Journal of the Institute of Metals, 90, (1961), pp. 21-22.

[68] D. McLean and M. H. Farmer, "The relation during creep between grain-boundary sliding, sub-crystal size, and extension," Journal of Institute of Metals, 85, (1956), pp. 41-50.

[69] P. Gay and A. Kelly, "X-ray studies of polycrystalline metals deformed by rolling. II. Examination of the softer metals, tin, zinc, lead and cadmium," Acta Crystallographica, 6, (1953), pp. 172-177.

[70] A. G. Guy, Elements of Physical Metallurgy, 2nd ed., London, 1960, Addison-Wesley Publishing Company Inc., $528 \mathrm{p}$.

[71] S. Miettinen, Recrystallization of Lead-free Solder Joints under Mechanical Load, Master's Thesis (in Finnish), Espoo, (2005), 84 p.

[72] T. M. Korhonen, L. Lehman, M. Korhonen, and D. Henderson, "Isothermal fatigue behavior of the near-eutectic $\mathrm{Sn}-\mathrm{Ag}-\mathrm{Cu}$ alloy between $-25^{\circ} \mathrm{C}$ and $125^{\circ} \mathrm{C}$," Journal of Electronic Materials, 36, 2, (2007), pp. 173-178.

[73] T. Laurila, T. T. Mattila, V. Vuorinen, J. Karppinen, J. Li, M. Sippola, and J. K. Kivilahti, "Evolution of microstructure and failure mechanism of lead-free solder interconnections in power cycling and thermal shock tests," Microelectronics Reliability, 47, 7, (2007), pp. 1135-44.

[74] T. T. Mattila, H. Xu, O. Ratia, and M. Paulasto-Kröckel, "Effects of thermal cycling parameters on lifetimes and failure mechanism of solder interconnections," The Proceedings of the 60th Electronic Component and Technology Conference, Las Vegas, NV, June 1-4, 2010, IEEE/EIA CPMT, (2010), pp. 581-590.

[75] H. Xu, T. T. Mattila, O. Ratia, and M. Paulasto-Kröckel, "Effects of thermal cycling parameters on lifetimes and failure mechanism of solder interconnections," IEEE Transactions on Manufacturing and Packaging Technologies - a Special Issue, (in print). Invited paper. 
[76] T. T. Mattila and J. K. Kivilahti, "The role of recrystallization in the failure mechanism of $\mathrm{SnAgCu}$ solder interconnections under thermomechanical loading," IEEE Transactions on Components and Packaging Technologies, 33, 3, (2010), pp. 629-635.

[77] J. Li, T. T. Mattila, and J. K. Kivilahti, "Multiscale simulation of recrystallization and grain growth of $\mathrm{Sn}$ in lead-free solder interconnections," Journal of Electronic Materials, 39, 1, (2010), pp. 77-84.

[78] J. Li, H. Xu, T. T. Mattila, J. K. Kivilahti, T. Laurila, and M. Paulasto-Kröckel, "Simulation of dynamic recrystallization in solder interconnections during thermal cycling," Computational Materials Science, 50, (2010), pp. 690-697. 


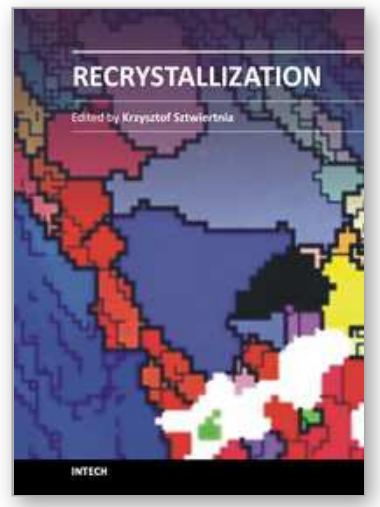

\author{
Recrystallization \\ Edited by Prof. Krzysztof Sztwiertnia
}

ISBN 978-953-51-0122-2

Hard cover, 464 pages

Publisher InTech

Published online 07, March, 2012

Published in print edition March, 2012

Recrystallization shows selected results obtained during the last few years by scientists who work on recrystallization-related issues. These scientists offer their knowledge from the perspective of a range of scientific disciplines, such as geology and metallurgy. The authors emphasize that the progress in this particular field of science is possible today thanks to the coordinated action of many research groups that work in materials science, chemistry, physics, geology, and other sciences. Thus, it is possible to perform a comprehensive analysis of the scientific problem. The analysis starts from the selection of appropriate techniques and methods of characterization. It is then combined with the development of new tools in diagnostics, and it ends with modeling of phenomena.

\title{
How to reference
}

In order to correctly reference this scholarly work, feel free to copy and paste the following:

Toni T. Mattila and Jorma K. Kivilahti (2012). The Failure Mechanism of Recrystallization - Assisted Cracking of Solder Interconnections, Recrystallization, Prof. Krzysztof Sztwiertnia (Ed.), ISBN: 978-953-51-0122-2, InTech, Available from: http://www.intechopen.com/books/recrystallization/the-failure-mechanism-ofrecrystallization-assisted-cracking-of-solder-interconnections

\section{INTECH}

open science | open minds

\section{InTech Europe}

University Campus STeP Ri Slavka Krautzeka 83/A 51000 Rijeka, Croatia Phone: +385 (51) 770447 Fax: +385 (51) 686166 www.intechopen.com

\section{InTech China}

Unit 405, Office Block, Hotel Equatorial Shanghai

No.65, Yan An Road (West), Shanghai, 200040, China 中国上海市延安西路65号上海国际贵都大饭店办公楼 405 单元 Phone: +86-21-62489820

Fax: +86-21-62489821 
(C) 2012 The Author(s). Licensee IntechOpen. This is an open access article distributed under the terms of the Creative Commons Attribution 3.0 License, which permits unrestricted use, distribution, and reproduction in any medium, provided the original work is properly cited. 